\title{
Field Testing of a Wet FGD Additive for Enhanced Mercury Control - Pilot-scale Test Results
}

\section{Topical Report}

\author{
Prepared by:
}

Gary M. Blythe

May 2006

Cooperative Agreement No: DE-FC26-04NT42309

\author{
URS Corporation \\ 9400 Amberglen Boulevard \\ Austin, Texas 78729 \\ Prepared for: \\ Charles Miller \\ National Energy Technology Laboratory \\ U.S. Department of Energy \\ 626 Cochrans Mill Road \\ Pittsburgh, Pennsylvania 15236
}





\section{DISCLAIMER}

This report was prepared as an account of work sponsored by an agency of the United States Government. Neither the United States Government nor any agency thereof, nor any of their employees, makes any warranty, express or implied, or assumes any legal liability or responsibility for the accuracy, completeness, or usefulness of any information, apparatus, product, or process disclosed, or represents that its use would not infringe privately owned rights. Reference herein to any specific commercial product, process, or service by trade name, trademark, manufacturer, or otherwise does not necessarily constitute or imply its endorsement, recommendation, or favoring by the United States Government or any agency thereof. The views and opinions of authors expressed herein do not necessarily state or reflect those of the United States Government or any agency thereof. 


\section{ABSTRACT}

This Topical Report summarizes progress on Cooperative Agreement DE-FC26-04NT42309, "Field Testing of a Wet FGD Additive." The objective of the project is to demonstrate the use of a flue gas desulfurization (FGD) additive, Degussa Corporation's TMT-15, to prevent the reemissions of elemental mercury $\left(\mathrm{Hg}^{0}\right)$ in flue gas exiting wet FGD systems on coal-fired boilers. Furthermore, the project intends to demonstrate that the additive can be used to precipitate most of the mercury $(\mathrm{Hg})$ removed in the wet FGD system as a fine TMT salt that can be separated from the FGD liquor and bulk solid byproducts for separate disposal.

The project will conduct pilot- and full-scale tests of the TMT-15 additive in wet FGD absorbers. The tests are intended to determine required additive dosage requirements to prevent $\mathrm{Hg}^{0} \mathrm{re}-$ emissions and to separate mercury from the normal FGD byproducts for three coal types: Texas lignite/Power River Basin (PRB) coal blend, high-sulfur Eastern bituminous coal, and low-sulfur Eastern bituminous coal.

The project team consists of URS Group, Inc., EPRI, TXU Generation Company LP, Southern Company, and Degussa Corporation. TXU Generation has provided the Texas lignite/PRB cofired test site for pilot FGD tests, Monticello Steam Electric Station Unit 3. Southern Company is providing the low-sulfur Eastern bituminous coal host site for wet scrubbing tests, as well as the pilot- and full-scale jet bubbling reactor (JBR) FGD systems to be tested. A third utility, to be named later, will provide the high-sulfur Eastern bituminous coal full-scale FGD test site. Degussa Corporation is providing the TMT-15 additive and technical support to the test program.

The project is being conducted in six tasks. Of the six project tasks, Task 1 involves project planning and Task 6 involves management and reporting. The other four tasks involve field testing on FGD systems, either at pilot or full scale. The four tasks include: Task 2 - Pilot Additive Testing in Texas Lignite Flue Gas; Task 3 - Full-scale FGD Additive Testing in Highsulfur Eastern Bituminous Flue Gas; Task 4 - Pilot Wet Scrubber Additive Tests at Yates; and Task 5 -Full-scale Additive Tests at Plant Yates. This topical report presents the results from the Task 2 and Task 4 pilot-scale additive tests. The Task 3 and Task 5 full-scale additive tests will be conducted later in calendar year 2006. 


\section{TABLE OF CONTENTS}

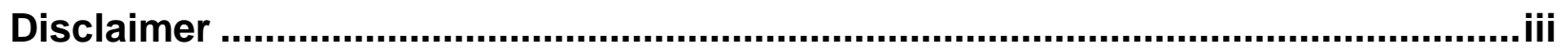

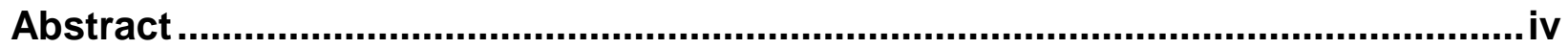

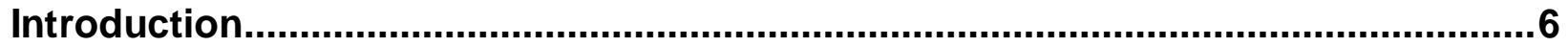

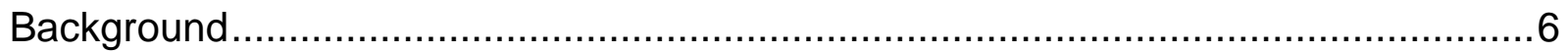

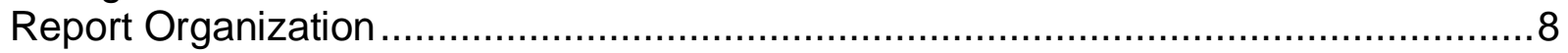

Experimental .................................................................................................................9

Task 2: Wet FGD Pilot Additive Tests at Monticello Station................................ 9

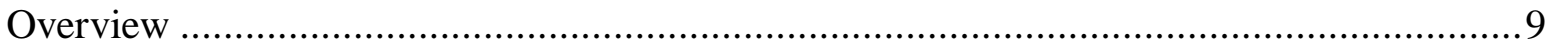

Description of Monticello Unit 3 ........................................................................ 9

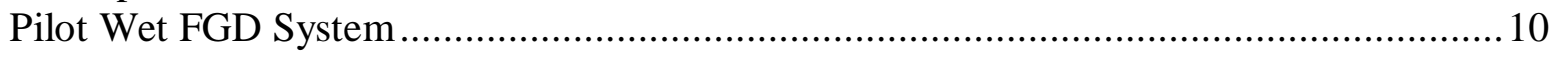

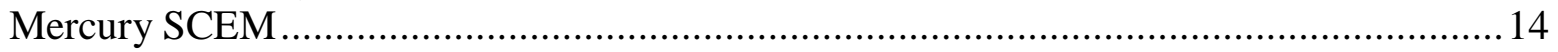

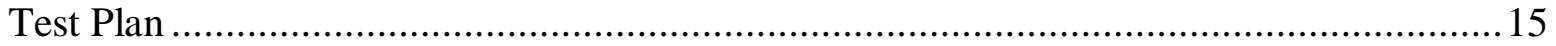

Task 4: Pilot JBR Additive Tests at Plant Yates .........................................16

Overview ................................................................................................... 16

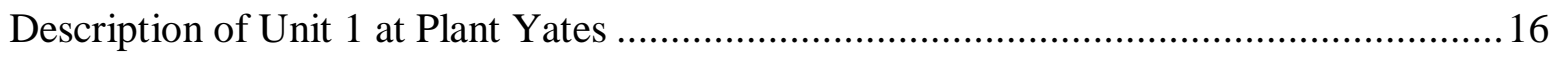

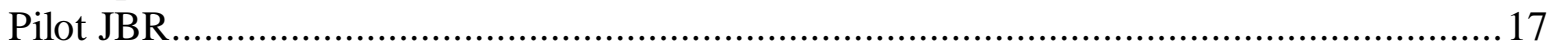

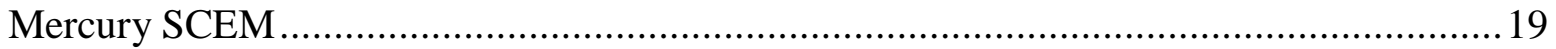

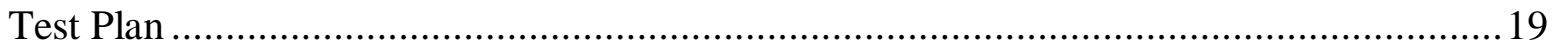

Results and Discussion ............................................................................................21

Task 2: Wet FGD Pilot Additive Tests at Monticello Station ...............................21

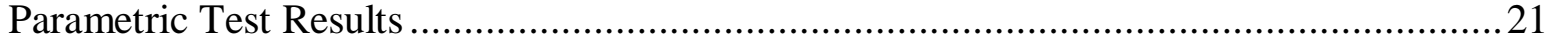

Mercury Removal Data ................................................................................ 21

Mercury Concentrations in FGD Liquor and Solids ...........................................22

FGD Solids Particle Size Analyses ................................................................24

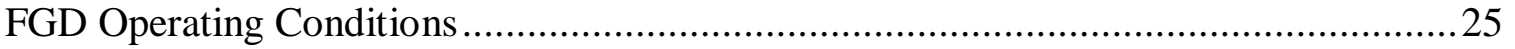

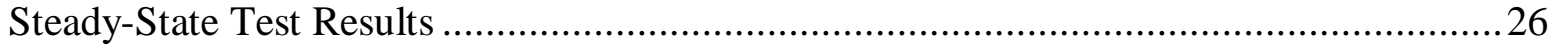

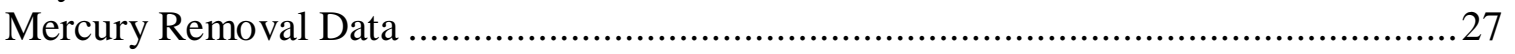

Mercury Concentrations in FGD Liquor and Solids .............................................. 31

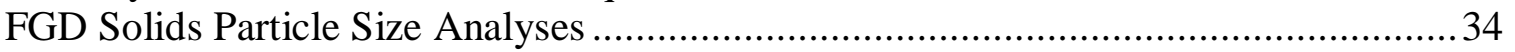

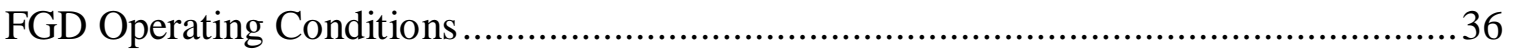

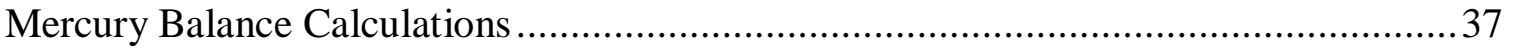

Task 4: Pilot JBR Parametric Additive Tests at Plant Yates...............................40

Mercury Removal Data ...................................................................................... 40

Mercury Concentrations in FGD Liquor and Solids ........................................... 41

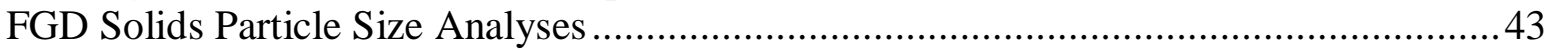

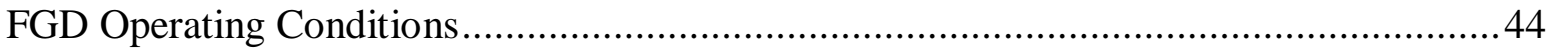

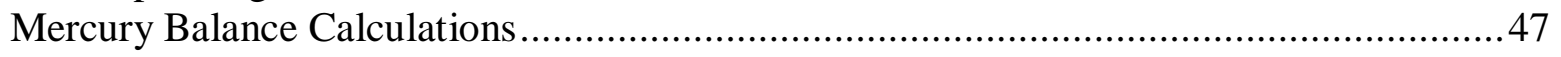

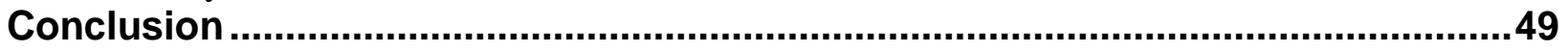

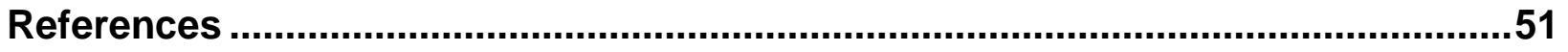




\section{INTRODUCTION}

This project is being conducted as part of NETL Cooperative Agreement DE-FC26-04NT42309, "Field Testing of a Wet FGD Additive." The objective of the project is to demonstrate the use of a flue gas desulfurization (FGD) additive, Degussa Corporation's TMT-15, to prevent the reemissions of elemental mercury $\left(\mathrm{Hg}^{0}\right)$ in flue gas exiting wet FGD systems on coal-fired boilers. Furthermore, the project intends to demonstrate that the additive can be used to precipitate most of the mercury $(\mathrm{Hg})$ removed in the wet FGD system as a fine TMT salt that can be separated from the FGD liquor and bulk solid byproducts for separate disposal.

The project will conduct pilot- and full-scale tests of the TMT-15 additive in wet FGD absorbers. The tests are intended to determine required additive dosage requirements to prevent $\mathrm{Hg}^{0}$ reemissions and to separate mercury from the normal FGD byproducts for three coal types: Texas lignite/Power River Basin (PRB) coal blend, high-sulfur Eastern bituminous coal, and low-sulfur Eastern bituminous coal.

The project team consists of URS Group, Inc. as the prime contractor, EPRI, TXU Generation Company LP, Southern Company, and Degussa Corporation. EPRI will provide technical input and co-funding. TXU Generation has provided the Texas lignite/PRB co-fired test site for pilot FGD tests, Monticello Steam Electric Station Unit 3, and is providing EPRI tailored collaboration project co-funding. Southern Company is providing the low-sulfur Eastern bituminous coal host site for wet scrubbing tests, as well as the pilot- and full-scale jet bubbling reactor (JBR) FGD systems to be tested. They are also providing on-site test support and management, and project co-funding through a tailored collaboration project with EPRI. A third utility, to be named later, will provide the high-sulfur Eastern bituminous coal full-scale FGD test site. Finally, Degussa Corporation is providing the TMT-15 additive and technical support to the test program.

The project is being conducted in six tasks. Of the six project tasks, Task 1 involves project planning and Task 6 involves management and reporting. The other four tasks involve field testing on FGD systems, either at pilot or full scale. The four tasks include: Task 2 - Pilot Additive Testing in Texas Lignite Flue Gas; Task 3 - Full-scale FGD Additive Testing in Highsulfur Eastern Bituminous Flue Gas; Task 4 - Pilot Wet Scrubber Additive Tests at Yates; and Task 5 -Full-scale Additive Tests at Plant Yates. This report presents the results from the Task 2 and Task 4 pilot-scale additive tests. The Task 3 and Task 5 full-scale additive tests will be conducted later in calendar year 2006.

\section{Background}

Many utility mercury emission compliance plans for coal-fired power plants incorporate the cobenefits of mercury capture in wet FGD systems. In wet FGD absorbers, the oxidized form of mercury $\left(\mathrm{Hg}^{+2}\right)$ is absorbed from the flue gas into the FGD liquor, while water insoluble elemental mercury $\left(\mathrm{Hg}^{0}\right)$ is typically not removed. Once absorbed, the oxidized mercury can follow as many as three pathways for leaving the FGD system. These include: 1) Undergoing reduction reactions while in the FGD liquor to form elemental mercury, which, being insoluble is released and re-emitted into the FGD outlet flue gas; 2) Being retained in the FGD liquor, and 
potentially becoming a regulatory compliance issue in FGD blow down liquor; or 3) Being retained in the FGD byproduct solids. This project is investigating the use of an FGD additive to rapidly precipitate mercury in FGD liquor as a solid salt, to minimize pathways 1 and 2. Pathway 3 may be the most desirable for FGD systems that landfill their FGD solid byproducts, but could become an issue if the byproducts are reused such as for wallboard production. A second objective of this project is to determine whether this same additive can be used to minimize mercury in reused FGD solid byproducts, through separation of the fine mercury-containing salts formed from the remainder of the byproduct.

The additive being tested in this project is a Degussa Corporation product, TMT-15. It is being tested as an FGD additive in both pilot- and full-scale trials. The intent of the TMT-15 additive is to precipitate absorbed mercury as a stable salt to minimize re-emissions and lower liquid-phase mercury concentrations, and for the salt to be removed from the solid FGD byproducts to lower their mercury content. While TMT-15 is used in Europe in such applications, it has not seen widespread use in U.S. plants. This project is providing an opportunity to evaluate the use of TMT-15 for these purposes on pilot- and full-scale wet FGD systems on U.S. coal-fired units. The following paragraphs provide further background on how TMT-15 has been used previously to control mercury emissions from FGD systems.

In some circumstances, mercury and other heavy metals must be removed from FGD blow down liquor before it can be discharged. A two-stage treatment has reportedly proven successful in Europe, using hydroxide precipitation followed by precipitation of the complexed metals with trimercapto-s-triazine, tri-sodium salt (TMT). TMT is commercially available from Degussa Corporation as a 15-wt \% aqueous solution, TMT 15. TMT is also used directly in wet FGD systems in a number of plants in Europe and worldwide to reduce mercury re-emissions. Mercury re-emissions occur when soluble $\mathrm{Hg}^{+2}$ reacts with sulfite ion (absorbed $\mathrm{SO}_{2}$ ) in wet FGD liquors and is reduced to the insoluble $\mathrm{Hg}^{0}$ form, which is released back into the FGD outlet flue gas. Conversion of $\mathrm{Hg}^{+2}$ to a non-volatile TMT salt before re-emission reactions occur can improve the overall mercury capture by the wet FGD system. TMT has reportedly been proven successful in this application worldwide in several hundred coal-fired power plants and municipal waste incinerators. Besides its ability to chemically bind with mercury, TMT reportedly has favorable toxicological and ecological properties. ${ }^{1}$

The reaction of TMT with heavy metals is based on the soluble tri-sodium salt chemically binding to heavy metals via the sulfur groups. In the process, high-molecular-weight organometallic compounds are produced which have a very low aqueous solubility. They precipitate as solid substances and can be separated from the liquor by filtration. The ionic reaction is nearly instantaneous and proceeds stoichiometrically. The active substance, trimercapto-s-triazine, reacts as a trivalent anion and can thus bind three cationic heavy metal equivalents. TMT reportedly reacts over a wide $\mathrm{pH}$ range, including acidic conditions, without decomposing or releasing toxic gases such as $\mathrm{H}_{2} \mathrm{~S}$.

In the FGD blow down slurry, fine particles of mercury-TMT compound are transferred to the wastewater/fines blow down, absorber recycle and/or partly to the byproduct gypsum. TMTmetal compounds are reportedly quite stable. Temperatures in excess of $210^{\circ} \mathrm{C}$ (which is well above the gypsum calcining temperature) are needed to begin to decompose the mercury-TMT 
salt, and TMT-metal compounds easily meet the leachability limits of the TCLP. It is anticipated that any mercury bound as a TMT salt that remains in FGD byproduct gypsum will remain stable and will not be volatilized into the flue gas in significant percentages when the gypsum is processed in a wallboard plant.

This project is intended to demonstrate the effectiveness of TMT-15 for these purposes in FGD systems installed on U.S. coal-fired power plants. As described above, the project will conduct two sets of pilot-scale TMT-15 additive tests and two full-scale TMT-15 additive trials. To date, only the pilot-scale tests have been conducted, and they are subsequently the subjects of this topical report.

\section{Report Organization}

The remainder of this report is organized into four sections: a section that describes Experimental procedures followed by sections for Results and Discussion, Conclusions, and References. 


\section{EXPERIMENTAL}

\section{Task 2: Wet FGD Pilot Additive Tests at Monticello Station}

\section{Overview}

In the first field effort, pilot-scale additive tests were conducted on Unit 3 at TXU Generation's Monticello Steam Electric Station, a 793-MW unit that fires a blend of $80 \%$ Texas lignite and 20\% PRB coal. Wet FGD additive parametric tests were conducted at Monticello in April 2005 on a 0.6-MW spray/tray FGD pilot unit built as part of another DOE co-funded project, DEFC26-04NT41992. The FGD pilot unit is further described below. The pilot FGD was operated in a limestone reagent, forced oxidation (LSFO) mode. TMT-15 solution was metered into the FGD slurry recycle pump discharge line with a small diaphragm pump.

Mercury semi-continuous emissions monitors (Hg SCEMs, also described below) were used to measure absorber inlet and outlet mercury concentrations and speciation, to quantify net mercury removal and mercury re-emissions under baseline (no TMT) and additive conditions. Mercury re-emissions were not seen from the pilot wet FGD when treating the flue gas at Monticello Unit 3 , so the ability of TMT-15 to prevent re-emissions could not be evaluated in these tests. Instead, the parametric tests focused on the ability to lower FGD liquor mercury concentrations and to produce a mercury-TMT salt that can be separated from the gypsum byproduct.

After conducting the parametric tests, it became apparent that to truly evaluate this latter objective, the pilot unit should have equipment to separate the fine mercury containing salts from the byproduct gypsum. To accomplish this, EPRI funded the addition of a hydrocyclone dewatering loop to the FGD pilot unit. This dewatering loop is described below along with the pilot wet FGD description.

The dewatering loop was constructed during the summer of 2005, and a second week of TMT-15 additive tests was conducted on the pilot unit at Monticello at the end of September. This test was conducted at a single TMT-15 dosage, selected based on previous pilot test results, and was intended to operate for a long enough period for the FGD byproduct solids to come to steady state with respect to mercury concentration. A second change for the "steady state" test was that it was conducted downstream of a gold mercury oxidation catalyst. The gold catalyst is being operated as part of Cooperative Agreement DE-FC26-04NT41992, and previous test results showed re-emissions from the wet FGD. It was decided that operating downstream of this catalyst, where re-emissions would be expected, would allow the ability of TMT-15 to control re-emissions to be evaluated.

\section{Description of Monticello Unit 3}

As mentioned above, Unit 3 at TXU Generation's Monticello Steam Electric Station is a 793MW unit that fires a blend of $80 \%$ Texas lignite and 20\% PRB coal. It has a horizontally opposed, pulverized coal boiler with low $\mathrm{NO}_{\mathrm{X}}$ burners. A cold-side electrostatic precipitator (ESP) is used for particulate control and a LSFO, open spray tower wet FGD system is used for $\mathrm{SO}_{2}$ control. The lignite/PRB blend contains $0.7 \mathrm{wt} \%$ sulfur, $0.14 \mathrm{ppm}$ mercury, and $210 \mathrm{ppm}$ chloride on average. The ESP outlet flue gas typically contains $25-50 \%$ oxidized mercury $\left(\mathrm{Hg}^{+2}\right)$ 
and the balance elemental mercury $\left(\mathrm{Hg}^{0}\right)$, with total mercury concentrations of about 20-30 $\mu \mathrm{g} / \mathrm{Nm}^{3}$. However, the Texas lignite has roughly four times the mercury content of the PRB on a mass basis, and the percentage of each fuel type fired cannot be closely controlled.

Consequently, variations in the percentage lignite versus PRB fired can greatly influence the flue gas mercury concentration and oxidation percentage.

\section{Pilot Wet FGD System}

The NETL co-funded 41992 project provided the opportunity to build a wet FGD pilot unit that is used to determine the ability to scrub catalytically oxidized mercury. The wet FGD pilot unit is designed to treat the flue gas from one of the four catalyst chambers on the mercury oxidation catalyst pilot unit, about $2000 \mathrm{acfm}$. It can be operated with lime or limestone reagent (usually provided by the host site full-scale wet FGD system reagent preparation system) and with inhibited, natural or forced oxidation. The flue gas contactor includes a single spray nozzle and a perforated plate tray. There is a single mist eliminator stage after the gas absorption section. The design basis for the pilot wet FGD system is summarized in Table 1. Figure 1 is a simplified piping and instrumentation diagram (P\&ID) for the pilot wet FGD system, and Figure 2 is a photograph of the wet FGD system as installed at Monticello Station.

The pilot FGD was installed to treat flue gas from downstream of the ESP on Monticello Unit 3. It could treat flue gas from either upstream or downstream of a mercury oxidation catalyst pilot unit also installed on Unit 3. The wet FGD pilot unit was operated using slurry from the fullscale FGD system at Monticello as the initial charge to the reaction tank; thus the testing started with near steady-state liquor and solids compositions. All of the testing was conducted in the LSFO mode, as the full-scale FGD system operates. Finely ground limestone reagent slurry from the full-scale system was used as makeup for the pilot FGD.

TMT-15 solution was metered into the FGD slurry recycle pump discharge line with a small diaphragm pump. The injection location is marked on the P\&ID in Figure 1. The solution flow was introduced through an existing pressure gauge fitting on the line. The TMT-15 solution was diluted, then pumped out of a 5-gallon plastic container placed on a digital weighing scale. Diluted TMT solution flow rates were set by adjusting the pump stroke, and verified by periodically noting the change in weight of the container. The TMT-15 injection rates were so low that dilution below the normal $15 \mathrm{wt} \%$ was required to get the injection rate up to a measurable and controllable value.

As mentioned above, a dewatering loop was added to treat the FGD blow down slurry for the steady state TMT test, so that fine mercury-TMT salts could be separated from the bulk gypsum byproduct. The hydrocyclone loop includes a Krebs 2-inch polyurethane hydrocyclone, a magnetic flow meter to measure the slurry feed rate to the hydrocyclone, a hydrocyclone feed pressure indicator, and a 200-gallon hydrocyclone underflow tank. The hydrocyclone overflow can be directed to a plant blow down sump or to the blow down holding tank on the pilot wet FGD skid. Figure 3 shows a schematic of the dewatering loop. 
Table 1. Pilot-scale Wet FGD Design Basis

\begin{tabular}{|c|c|}
\hline Design Feature & Value \\
\hline \multicolumn{2}{|l|}{ Gas Conditions: } \\
\hline Flue Gas flow rate & $2000 \mathrm{acfm}$ \\
\hline Inlet $\mathrm{SO}_{2}$ concentration & 2000 ppmv max, 1000 ppm or less normal \\
\hline Inlet temperature & $300^{\circ} \mathrm{F}$ \\
\hline Design $\mathrm{SO}_{2}$ removal percentage & $\begin{array}{l}\sim 95 \% \text { (varies with inlet } \mathrm{SO}_{2} \text {, reagent ratio, LS grind, } \\
\text { chloride concentration in slurry liquor) }\end{array}$ \\
\hline \multicolumn{2}{|l|}{ Scrubber Design Criteria: } \\
\hline Contactor type & Spray/tray \\
\hline Flue gas inlet ductwork & 10-in. through inlet venturi, 14 -in. at wet/dry interface \\
\hline Booster fan sizing & $2000 \mathrm{acfm}$ at $14-\mathrm{in} . \mathrm{H}_{2} \mathrm{O}$ differential \\
\hline Tray open area & $24 \%$ \\
\hline Tray hole diameter & $1.375 \mathrm{in.}$ \\
\hline L/G ratio & $127 \mathrm{gal} / \mathrm{kacf} \max$ \\
\hline Mist eliminator type & Single stage, Koch Otto York, Style VIII-3-1.5 \\
\hline Oxidation air rate, $\max \mathrm{O} / \mathrm{SO}_{2}$ ratio & 10 at 2000 ppmv inlet $\mathrm{SO}_{2}$ \\
\hline \multicolumn{2}{|l|}{ Tank Sizing: } \\
\hline Reaction tank dimensions & 6-ft dia. x 8-ft, covered, baffled, single top-entry agitator \\
\hline Reaction tank solids residence time & 18 -hr at $2000 \mathrm{ppmv}$ inlet $\mathrm{SO}_{2}, 35-\mathrm{hr}$ at $1000 \mathrm{ppmv}$ \\
\hline Reaction tank liquid holdup, minimum & 7.4 minutes \\
\hline Reagent tank dimensions & 3-ft dia. x 6-ft, open top, baffled, single top-entry agitator \\
\hline Reagent tank storage capacity, hrs supply & 14-hr at $2000 \mathrm{ppmv}$ inlet $\mathrm{SO}_{2}, 27-\mathrm{hr}$ at $1000 \mathrm{ppmv}$ \\
\hline Blow down tank dimensions & 5-ft dia. $\times 8$-ft, open top, baffled, single top-entry agitator \\
\hline $\begin{array}{l}\text { Blow down tank storage capacity, hrs of } \\
\text { FGD operation }\end{array}$ & 13-hr at $2000 \mathrm{ppmv}$ inlet $\mathrm{SO}_{2}, 25-\mathrm{hr}$ at $1000 \mathrm{ppmv}$ \\
\hline \multicolumn{2}{|l|}{ Instrumentation: } \\
\hline Flow rate & Inlet flue gas venture \\
\hline Temperature & Inlet flue gas, outlet flue gas, reaction tank slurry \\
\hline Pressure & Inlet flue gas, recycle slurry, oxidation air \\
\hline Pressure drop & $\begin{array}{l}\text { Gas flow rate venturi, absorber spray/tray section, } \\
\text { absorber ME }\end{array}$ \\
\hline Level & Reaction tank, reagent tank, blow down tank \\
\hline $\mathrm{pH}$ & Reaction tank slurry \\
\hline Mercury concentration & $\begin{array}{l}\text { Absorber inlet/outlet sample ports, heat-traced tubing, IGS } \\
\text { filter }\end{array}$ \\
\hline
\end{tabular}




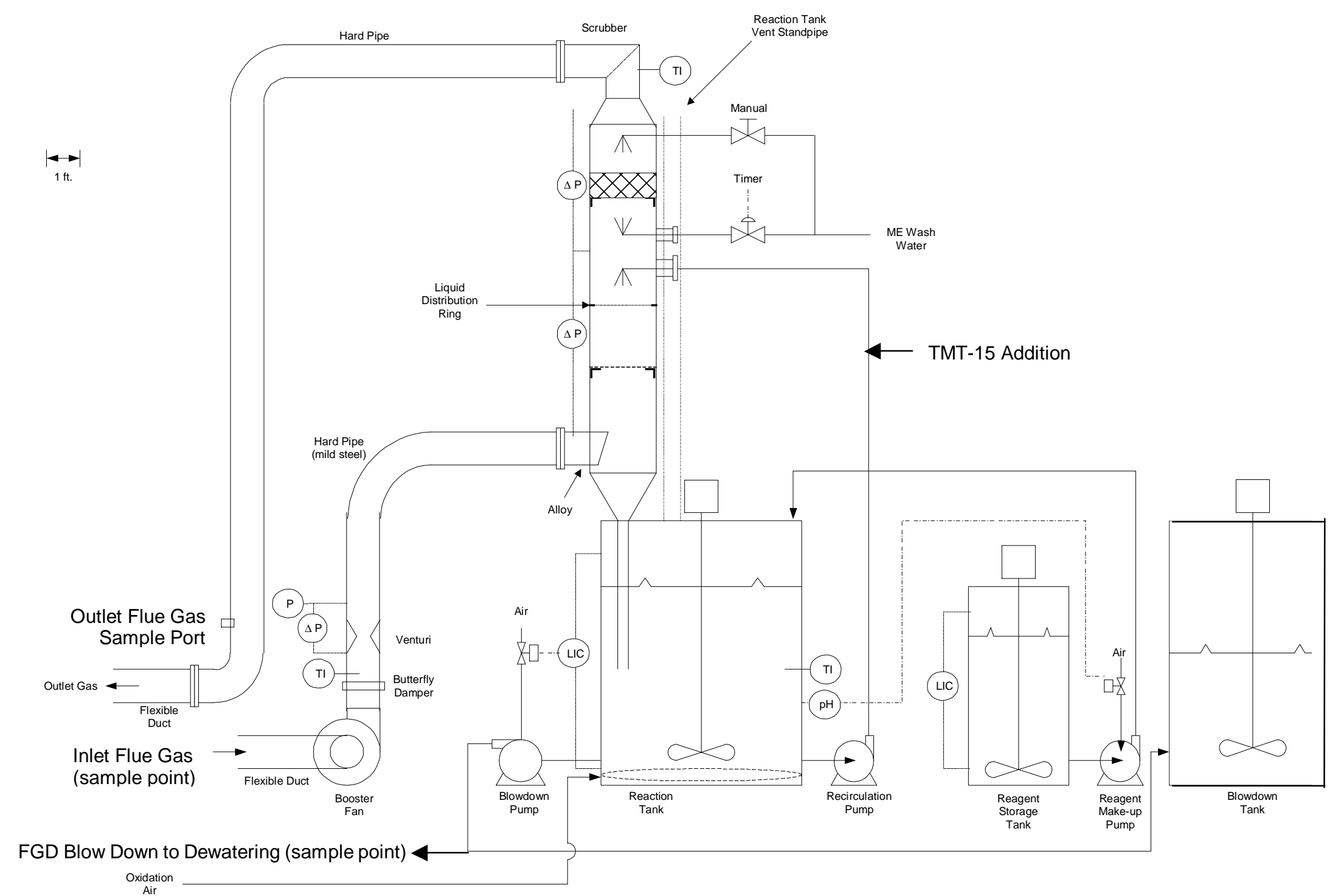

Figure 1. Simplified P\&ID for Pilot Wet FGD System 


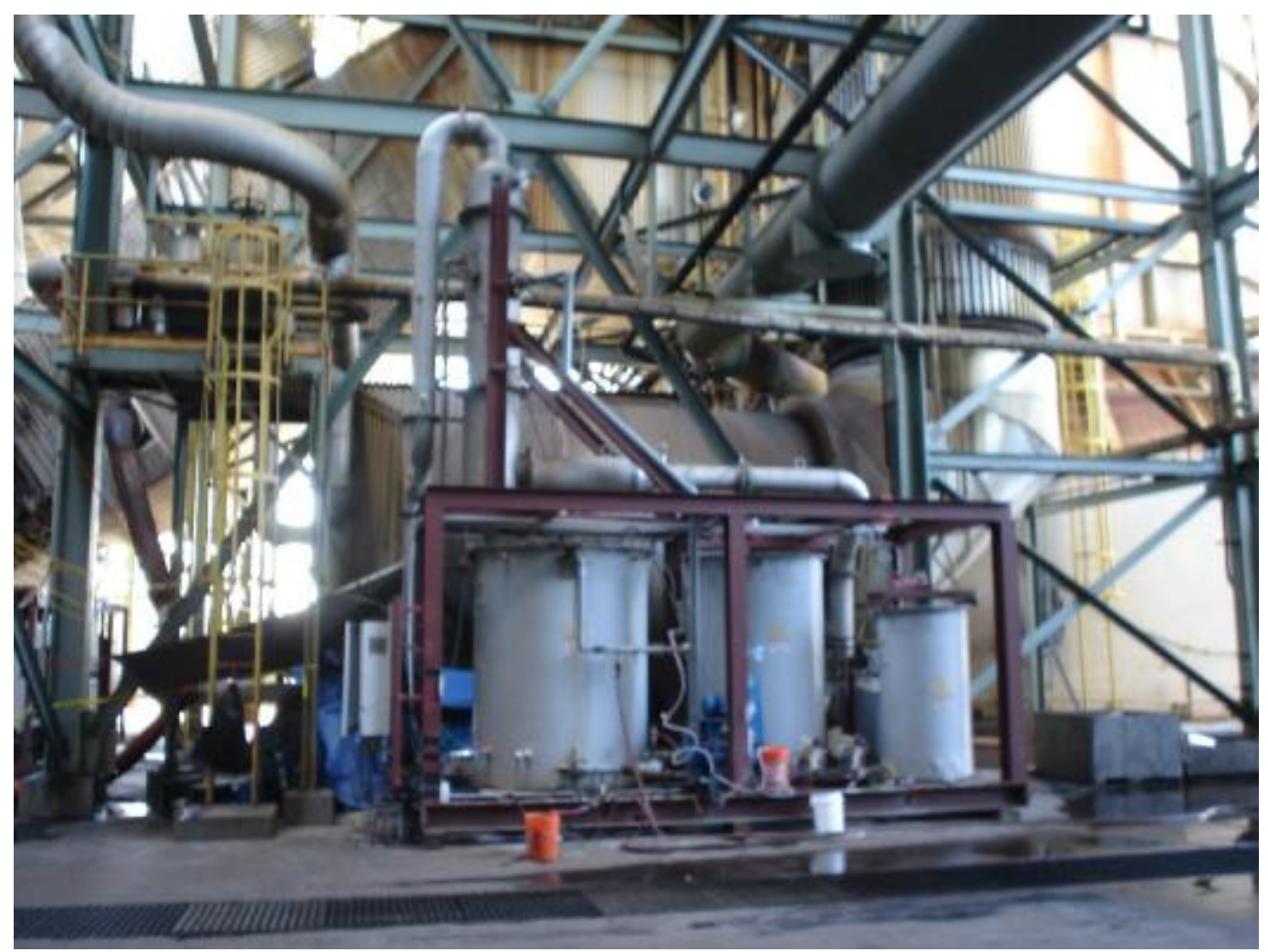

Figure 2. Photo of the Wet FGD Pilot Unit at Monticello Station

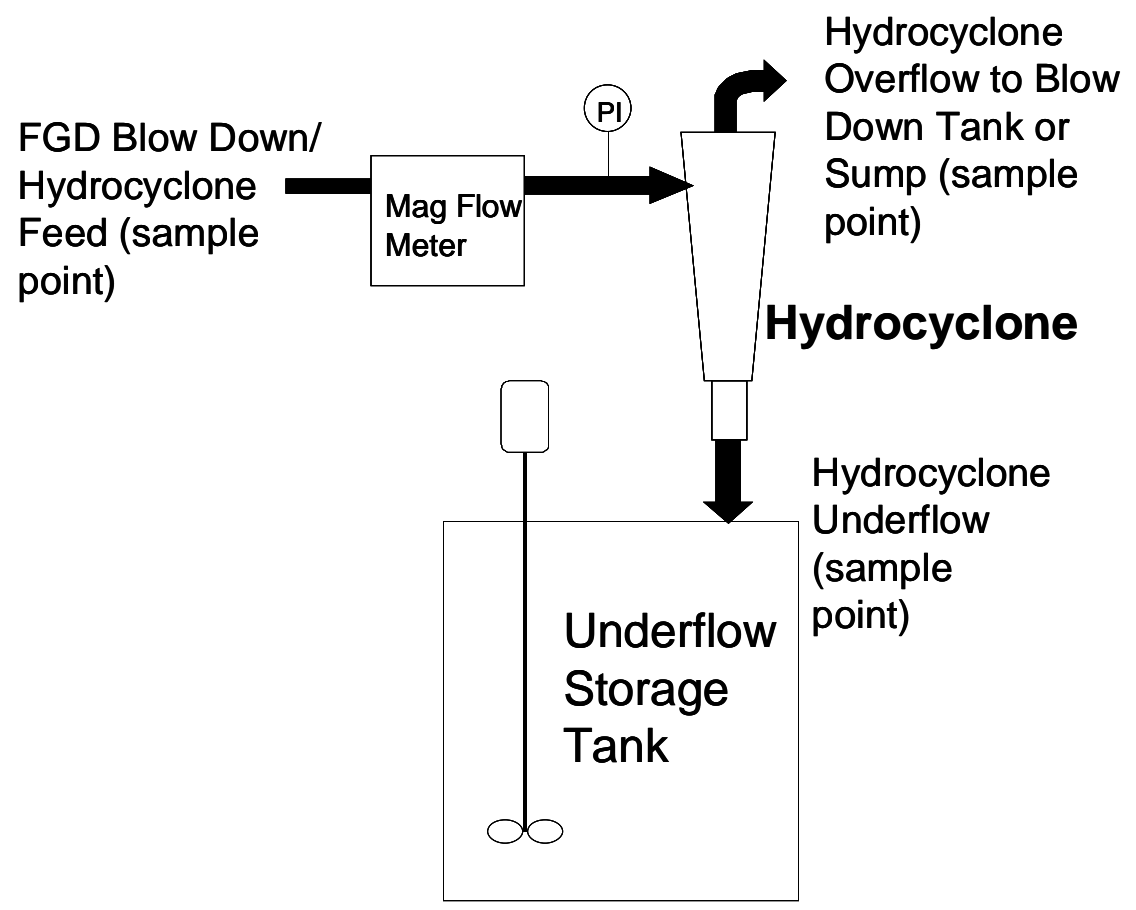

Figure 3. Schematic of FGD Blow Down Dewatering Loop 


\section{Mercury SCEM}

During pilot FGD operation, flue gas mercury measurements were made using a mercury SCEM developed for EPRI, as illustrated in Figure 4. Flue gas was pulled from an inertial gas separator (IGS) filter installed at either the FGD absorber inlet or outlet location. The IGS filter consists of a heated stainless steel tube lined with sintered material. A blower is used to pull a flue gas sample at high velocity through the sintered metal section. A secondary sample stream is pulled across the sintered metal filter at a rate of about $1 \mathrm{~L} / \mathrm{min}$ and then is directed to the mercury analyzer through a series of impinger solutions using a Teflon-lined pump.

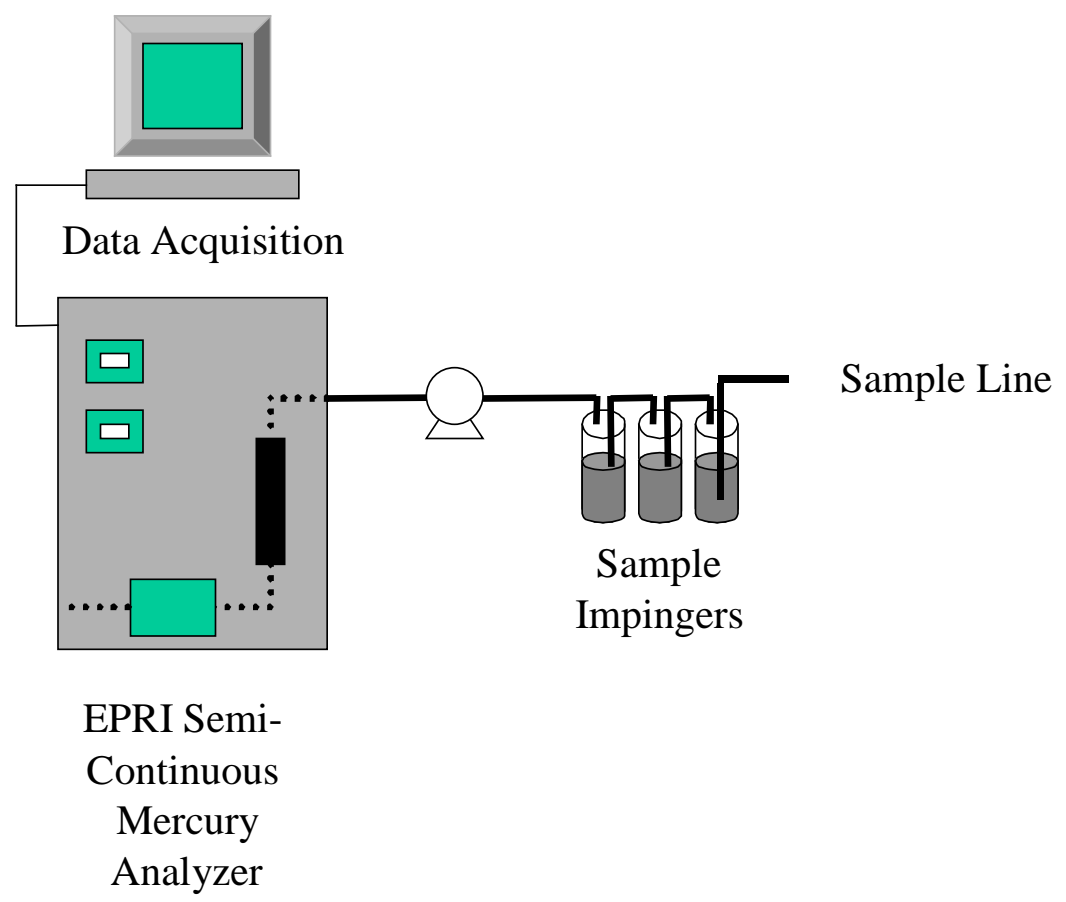

Figure 4. Schematic of Mercury SCEM

To measure total mercury in the flue gas, the impinger solutions consist of stannous chloride $\left(\mathrm{SnCl}_{2}\right)$ followed by a sodium carbonate $\left(\mathrm{Na}_{2} \mathrm{CO}_{3}\right)$ buffer and sodium hydroxide $(\mathrm{NaOH})$. The $\mathrm{SnCl}_{2}$ solution reduces all flue gas mercury species to elemental mercury. After passing through the $\mathrm{SnCl}_{2}$ impinger, the gas flows through the $\mathrm{Na}_{2} \mathrm{CO}_{3}$ and $\mathrm{NaOH}$ solutions to remove acid gases, thus protecting the downstream, analytical gold surface.

Gas exiting the impinger solutions flows through a gold amalgamation column, where the mercury in the gas is adsorbed at less than $100^{\circ} \mathrm{C}$. After adsorbing mercury onto the gold for a fixed period of time (typically 1 to 5 minutes), the mercury concentrated on the gold is thermally desorbed $\left(>700^{\circ} \mathrm{C}\right)$ from the column into clean air. The desorbed mercury is sent as a concentrated stream to a cold-vapor atomic absorption spectrophotometer (CVAAS) for analysis. The total flue gas mercury concentration is measured semi-continuously, typically with a one- to five-minute sample time followed by a one- to two-minute analytical period. 
To measure elemental mercury in the flue gas, the stannous chloride impinger is replaced with an impinger containing either tris(hydroxymethyl)aminomethane (Tris) or potassium chloride $(\mathrm{KCl})$ solution. The Tris solution has been shown in previous EPRI studies to capture oxidized mercury while allowing elemental mercury to pass through without being altered. $\mathrm{KCl}$ is used to collect oxidized mercury in the Ontario Hydro train. Mercury passing through the Tris or $\mathrm{KCl}$ solution to the gold is analyzed as described above and assumed to be elemental mercury only. The difference between the total mercury concentration (stannous chloride solution) and elemental mercury concentration (Tris or $\mathrm{KCl}$ solution) is assumed to be the oxidized mercury concentration.

Two analyzers are typically used to semi-continuously monitor FGD inlet and outlet gas mercury concentrations. The analyzers are switched intermittently between sampling for elemental versus total mercury concentrations.

\section{Test Plan}

Table 2 summarizes sampling and analysis plan for this testing. During both the parametric and steady state test weeks, mercury removal and speciation data were collected across the pilot FGD on day shift using the Hg SCEM, as described later in this section. Over the last two days of the extended-duration test in the second test week, triplicate Ontario Hydro method measurements were made at the pilot unit inlet and outlet.

Each test day, one set of FGD reaction tank/blow down liquor and reaction tank/blow down solid/slurry samples was collected and preserved. Preservation techniques involved immediate filtering to separate the slurry liquor from the solids, then adding preserving solutions to the liquor portion to prevent precipitation, oxidation, or other chemical reactions of the analyte(s) of interest. No further preservation was required for the solids once separated from the liquor.

During the steady-state tests where dewatering equipment was available, hydrocyclone overflow and underflow samples were also collected. For the first week of parametric tests, the fines solids and bulk gypsum were separated on the basis of particle size by settling in the laboratory, and mercury concentrations were measured by size fraction.

These samples were analyzed off site for mercury and FGD species concentrations, and for particle size distributions in the solids. These results were used to determine any impacts of the additive on FGD chemistry (e.g., reagent utilization or sulfite oxidation) and to construct cursory mercury balances around the FGD system, including how the mercury phase separates between the liquor, fine solids and bulk gypsum. 
Table 2. Sampling and Analysis Activities for Monticello Wet FGD Pilot Additive Tests

\begin{tabular}{|c|c|c|c|}
\hline Location & Sample Type & Frequency & Planned Analyses* \\
\hline \multirow[t]{2}{*}{ FGD inlet/outlet } & \multirow[t]{2}{*}{ Flue gas } & Daily, day shift & $\begin{array}{l}\mathrm{Hg} \text { concentration and } \\
\text { speciation by Hg SCEM }\end{array}$ \\
\hline & & $\begin{array}{l}\text { Triplicate runs, } \\
\text { Thursday/Friday of } \\
\text { week } 2\end{array}$ & $\begin{array}{l}\text { Hg concentration and } \\
\text { speciation by Ontario } \\
\text { Hydro method }\end{array}$ \\
\hline FGD reagent & Slurry & Once per week & Hg concentration \\
\hline FGD makeup water & Liquor & Once per week & Hg concentration \\
\hline $\begin{array}{l}\text { FGD reaction tank/ } \\
\text { blow down liquor }\end{array}$ & $\begin{array}{l}\text { Filtered and preserved } \\
\text { liquor }\end{array}$ & Daily & $\begin{array}{l}\text { FGD chemistry, } \mathrm{Hg} \\
\text { concentration }\end{array}$ \\
\hline \multirow[t]{2}{*}{$\begin{array}{l}\text { FGD reaction tank/ } \\
\text { blow down solids }\end{array}$} & $\begin{array}{l}\text { Filtered and preserved } \\
\text { slurry solids }\end{array}$ & Daily & Hg concentration \\
\hline & Whole slurry sample & Daily & $\begin{array}{l}\text { Wt\% solids, } \mathrm{Hg} \\
\text { concentration, FGD } \\
\text { chemistry }\end{array}$ \\
\hline $\begin{array}{l}\text { FGD reaction tank/ } \\
\text { blow down fines }\end{array}$ & $\begin{array}{l}\text { Whole slurry sample, } \\
\text { wet sieved off site }\end{array}$ & Daily & $\begin{array}{l}\text { Hg concentration, particle } \\
\text { size, wt } \% \text { of whole slurry, } \\
\text { SPLP }\end{array}$ \\
\hline $\begin{array}{l}\text { FGD reaction tank/ } \\
\text { blow down bulk solids }\end{array}$ & $\begin{array}{l}\text { Whole slurry sample, } \\
\text { wet sieved off site } \\
\text { (multiple size fractions) }\end{array}$ & Daily & $\begin{array}{l}\text { Hg concentration, particle } \\
\text { size, wt } \% \text { of whole slurry }\end{array}$ \\
\hline
\end{tabular}

*Only a selected subset of daily samples were analyzed

\section{Task 4: Pilot JBR Additive Tests at Plant Yates}

\section{Overview}

A second field effort was to conduct wet FGD additive tests at Southern Company's Georgia Power Plant Yates. Tests were conducted on a pilot-scale jet bubbling reactor (JBR) wet FGD absorber installed on Unit 1 at Plant Yates. Two weeks of pilot-scale additive screening tests were conducted in August 2005. Hg SCEMs were used to measure absorber inlet and outlet mercury concentrations and speciation to quantify net mercury removal and mercury reemissions under baseline (no TMT) and additive conditions. The primary test variable was the TMT-15 dosage rate.

\section{Description of Unit 1 at Plant Yates}

Unit 1 at Plant Yates is rated at nominally 123-MW of generating capacity, and fires $1 \%$ sulfur, Eastern bituminous coal. The coal contains an average of $0.05 \mathrm{ppm}$ of mercury and $220 \mathrm{ppm}$ of chloride. The ESP outlet flue gas typically contains about $60 \% \mathrm{Hg}^{+2}$ and $40 \% \mathrm{Hg}^{0}$ at a total concentration of $10 \mu \mathrm{g} / \mathrm{Nm}^{3}$ or less. The host unit has a tangentially fired PC boiler and uses a 
small cold-side ESP with gas conditioning for particulate control, and the CT-121 wet FGD process, which employs a JBR flue gas contactor, for $\mathrm{SO}_{2}$ control.

Figure 5 shows a simplified schematic of a JBR. A JBR configuration is different than a conventional spray/tray absorber tower, such as was tested at Monticello, in that there is not a high-volume slurry recycle from a reaction tank to nozzles in the absorber vessel. Instead, in a JBR the flue gas is bubbled into the FGD slurry through downcomer tubes to result in intimate gas/slurry contacting. Limestone slurry is added in the upper, absorption zone of the JBR, and FGD byproduct slurry is withdrawn from a lower, reaction zone of the JBR. A small slurry recycle stream (not shown in the figure) is used to quench the flue gas before it enters the JBR.

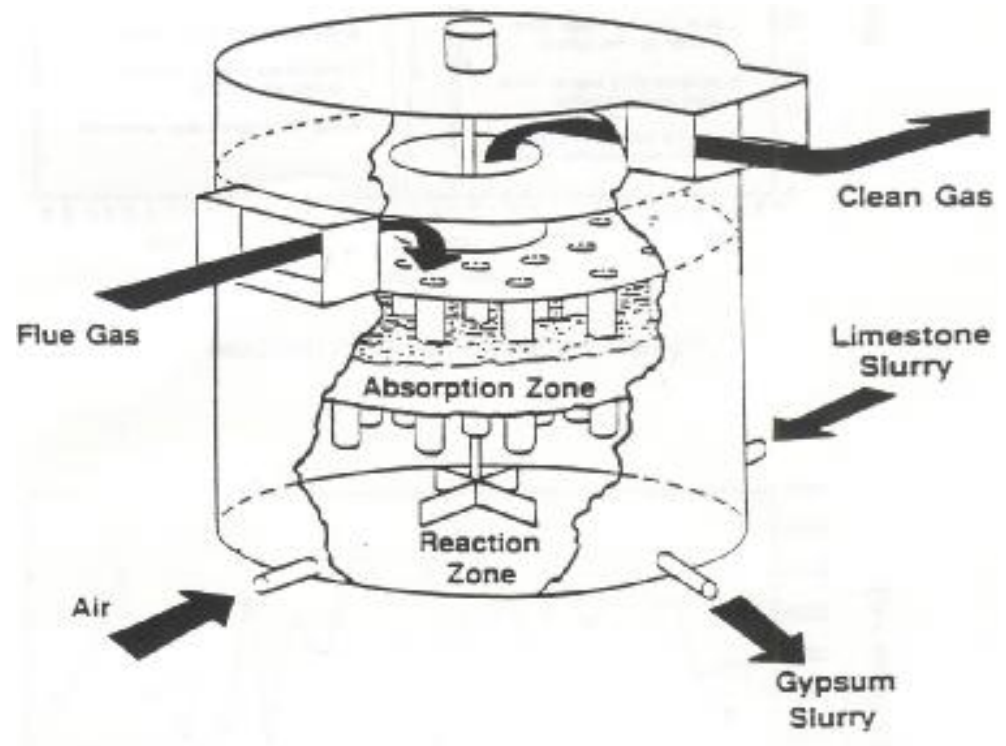

Figure 5. Simplified Schematic of a JBR

Source: Burford et al, "Plant Yates ICCT CT-121 Demonstration Results of Parametric Testing," 1993

\section{Pilot JBR}

Figure 6 is a schematic of the pilot JBR, which is trailer mounted. It is sized to treat a flue gas flow rate of 2,725 acfm at saturated gas (scrubber outlet) conditions. It was previously installed as a "polishing," clear solution (i.e., not a slurry) scrubber downstream of the full-scale JBR for another test program at Plant Yates. For the TMT-15 additive tests, the pilot JBR was reconfigured in parallel with the full-scale JBR to treat hot, $\mathrm{SO}_{2}$-containing flue gas. That is, the pilot JBR inlet duct was re-routed to originate upstream of the full-scale JBR rather than downstream. The pilot JBR was also modified to add a slurry pump to feed slurry to the spray nozzles shown for flue gas quenching during LSFO operation. An existing spray liquor recycle vessel was blanked off, and the mist eliminator upstream of the pilot JBR was removed. These changes better simulate the configuration of the full-scale JBR. Finally, forced oxidation air was added at the bottom of the pilot JBR through spargers spaced around its circumference. Figure 6 reflects all of these modifications made to the pilot JBR prior to the TMT tests. 


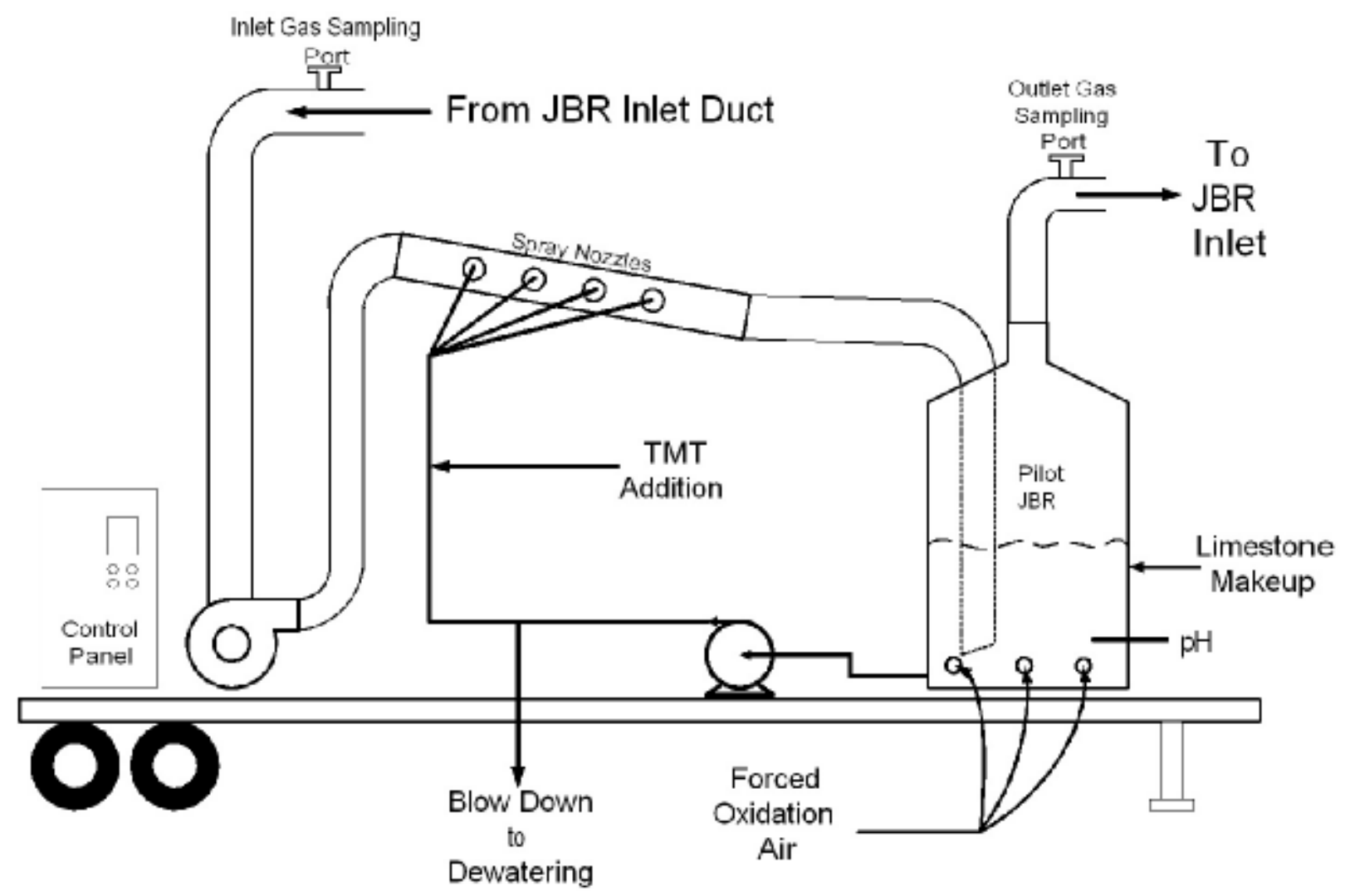

Figure 6. Schematic of 1-MW Pilot JBR Wet FGD

The EPRI hydrocyclone dewatering loop, as described above for the Monticello tests and illustrated in Figure 3, was also used to separate mercury-TMT fines from the gypsum byproduct in the pilot JBR blow down slurry. However, the magnetic flow meter was not available at the time of the Yates testing, so the hydrocyclone feed rate was adjusted to achieve a desired hydrocyclone inlet pressure reading.

As described above for the full-scale system, in a JBR there is not a high-volume recirculating slurry stream as in a spray/tray tower that would be an equivalent injection point for TMT. There is, however, a small slurry recycle stream used to quench the flue gas before it enters the JBR downcomer tubes. For these pilot tests, the TMT-15 was added with the small quench slurry stream.

Two items not included in the pilot JBR had an adverse effect on pilot additive test results, as will be discussed in the following section. One item not included was a mechanical agitator in the reaction zone. It was thought by Southern Company personnel, who readied the pilot unit for LSFO operation, that the action of forced oxidation air, introduced through spargers around the circumference of the JBR in the reaction zone, would be adequate to keep the slurry well mixed. However, this did not prove to be the case, and evidence was seen of poor mixing of the JBR slurry during the tests.

For example, the slurry $\mathrm{pH}$ was measured with an insertion-style $\mathrm{pH}$ probe mounted to the side of the JBR up in the absorption zone. The measurement and control of slurry $\mathrm{pH}$ was observed to 
be quite sluggish during these tests, with the $\mathrm{pH}$ being slow to increase when fresh limestone slurry was made up, and slow to drop as the limestone was utilized. Also, slurry blow down from the JBR was taken as a slipstream of the slurry being pumped from the reaction zone up to the flue gas quench nozzles in the duct upstream of the JBR. Samples taken from this steam showed inconsistent results with respect to $\mathrm{pH}$, weight percent solids, and apparent limestone utilization.

Another item not included in the pilot JBR was a mist eliminator. It was felt that since the flue gas exiting the pilot JBR was being ducted directly into the full-scale JBR, removal of mist carryover would not be necessary. However, as described below, the high apparent mist loading in the pilot JBR outlet gas interfered with the ability to measure the outlet flue gas mercury concentration and speciation.

\section{Mercury SCEM}

The same mercury SCEMs as described above for the Monticello tests were used to measure mercury removal across the pilot JBR. One SCEM was used to monitor the pilot JBR inlet gas and the other to monitor the outlet gas. Please refer to the previous discussion for a description of these devices.

As mentioned in the previous subsection, the pilot JBR did not have a mist eliminator for the outlet gas, which led to considerable entrained mist in the flue gas being sampled at the outlet location by the mercury SCEM. This, in turn, led to measurement problems with the pilot JBR outlet gas sample. Because the IGS filter used in the mercury SCEM sampling train is heated to minimize mercury adsorption by solids in the sample gas, it is speculated that this heating led to evaporation of mist carryover liquor, releasing aqueous mercury, and desorption of mercury from mist carryover solids. As a result, the pilot JBR outlet flue gas Hg SCEM results from these tests are not believed to be representative.

\section{Test Plan}

Table 3 summarizes the sampling and analytical activities that were planned for the pilot JBR tests conducted at Plant Yates. 
Table 3. Planned Sampling and Analysis Activities for Yates JBR Pilot Additive Tests

\begin{tabular}{|c|c|c|c|}
\hline Location & Sample Type & Frequency & Planned Analyses* \\
\hline JBR inlet/outlet & Flue gas & Daily, day shift & $\begin{array}{l}\text { Hg concentration and } \\
\text { speciation by } \mathrm{Hg} \\
\text { SCEM }\end{array}$ \\
\hline Limestone reagent & Slurry & Once per week & Hg concentration \\
\hline JBR makeup water & Liquor & Once per week & Hg concentration \\
\hline $\begin{array}{l}\text { JBR blow down slurry } \\
\text { liquor }\end{array}$ & $\begin{array}{l}\text { Filtered and preserved } \\
\text { liquor }\end{array}$ & Daily & $\begin{array}{l}\text { FGD chemistry, } \mathrm{Hg} \\
\text { concentration }\end{array}$ \\
\hline \multirow[t]{2}{*}{$\begin{array}{l}\text { JBR blow down slurry } \\
\text { solids }\end{array}$} & $\begin{array}{l}\text { Filtered and preserved } \\
\text { slurry solids }\end{array}$ & Daily & Hg concentration \\
\hline & Whole slurry sample & Daily & $\begin{array}{l}\text { Wt\% solids, Hg } \\
\text { concentration, FGD } \\
\text { chemistry }\end{array}$ \\
\hline $\begin{array}{l}\text { JBR blow down slurry } \\
\text { fines (Hydrocyclone } \\
\text { overflow) }\end{array}$ & $\begin{array}{l}\text { Filtered and preserved } \\
\text { liquor and solids; } \\
\text { Whole slurry sample }\end{array}$ & Daily & $\begin{array}{l}\text { Hg concentration by } \\
\text { phase, particle size, } \\
\text { wt } \% \text { solids }\end{array}$ \\
\hline $\begin{array}{l}\text { JBR blow down slurry } \\
\text { gypsum product solids } \\
\text { (Hydrocyclone } \\
\text { underflow) }\end{array}$ & $\begin{array}{l}\text { Filtered and preserved } \\
\text { liquor and solids; } \\
\text { Whole slurry sample }\end{array}$ & Daily & $\begin{array}{l}\mathrm{Hg} \text { concentration by } \\
\text { phase, particle size, } \\
\text { wt } \% \text { solids }\end{array}$ \\
\hline
\end{tabular}

*Only a selected subset of daily samples to be analyzed 


\section{RESULTS AND DISCUSSION}

This section provides details of technical results for pilot-scale TMT additive tests conducted on the two wet FGD pilot units described in the previous section. Results from each site are described in separate subsections.

\section{Task 2: Wet FGD Pilot Additive Tests at Monticello Station}

\section{Parametric Test Results}

TMT-15 parametric test were conducted at TXU's Monticello Unit 3 in April 2005, using the 0.6-MW pilot wet FGD system described in the previous section and operating in LSFO mode. The second week, consisting of a steady-state pilot TMT additive test, also in LSFO mode, was conducted at Monticello Unit 3 in late September.

The one-week parametric test included baseline (no TMT) performance and four subsequent tests at increasing dosage rates of TMT-15. Degussa's reporting convention for TMT dosage is in "mL/ton of coal fired," where the $\mathrm{mL}$ dosage is as $15 \mathrm{wt} \%$ solution. The dosages tested included $0,5,10,20$ and $40 \mathrm{~mL} /$ ton of coal.

\section{Mercury Removal Data}

Baseline (no TMT addition) mercury removal data were measured for the pilot wet FGD system by mercury SCEM, using one analyzer each at the FGD inlet and outlet. These baseline results from April 25, summarized in Table 4, showed no evidence of mercury re-emissions (which would be seen as an increase in $\mathrm{Hg}^{0}$ concentration across the FGD absorber). Instead, the results show significant removal of $\mathrm{Hg}^{0}$, which was not expected since it is primarily oxidized mercury $\left(\mathrm{Hg}^{+2}\right)$ that is removed by wet scrubbers. The results also show a lower than expected removal percentage of $\mathrm{Hg}^{+2}$. Together, these two observations suggest that at the pilot FGD outlet location, the sample conditioning system for the mercury SCEM was oxidizing elemental mercury in the sample gas being delivered to the analyzer. This would produce a low bias for observed $\mathrm{Hg}^{+2}$ removal and a high bias for $\mathrm{Hg}^{0}$ removal. Evidence of such a bias was seen in previous results for the outlet of this pilot wet FGD system when comparing Ontario Hydro method and SCEM results as part of another DOE-sponsored project. ${ }^{2}$

However, in spite of this suspected bias, it is apparent that the pilot wet FGD was removing some $\mathrm{Hg}^{0}$. If only $\mathrm{Hg}^{+2}$ is removed by the wet FGD system, the inlet flue gas mercury oxidation percentage should represent an upper limit for the overall mercury capture percentage. The results in Table 4 show that the overall $\mathrm{Hg}$ capture percentage across the pilot wet FGD was higher than the inlet flue gas percent oxidation, indicating that some $\mathrm{Hg}^{0}$ was being removed. Note that previous Ontario Hydro results for baseline (no TMT addition) testing, conducted with this pilot unit as part of another project mentioned above, also showed no evidence of reemissions and a small percentage capture of $\mathrm{Hg}^{0}{ }^{2}$ So, these aspects of the SCEM results have been confirmed by another measurement method. 
Table 4. Pilot FGD Mercury Removal Data, by SCEM

\begin{tabular}{|c|c|c|c|c|c|c|c|c|c|c|}
\hline \multirow{2}{*}{\multicolumn{2}{|c|}{ Date }} & \multirow{3}{*}{ 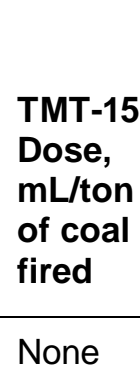 } & \multicolumn{2}{|c|}{$\begin{array}{l}\text { Pilot Unit } \\
\text { Inlet } \mathrm{Hg} \text {, } \\
\mu \mathrm{g} / \mathrm{Nm}^{3} @ \\
3 \% \mathrm{O}_{2}\end{array}$} & \multicolumn{2}{|c|}{$\begin{array}{l}\text { FGD Outlet } \\
\mathrm{Hg}, \mu \mathrm{g} / \mathrm{Nm}^{3} \\
@ 3 \% \mathrm{O}_{2}\end{array}$} & \multirow{3}{*}{$\begin{array}{l}\mathrm{Hg} \\
\text { Oxidation } \\
\text { at Pilot } \\
\text { Inlet, \% } \\
27 \%\end{array}$} & \multirow{3}{*}{ 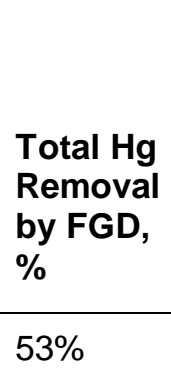 } & \multirow{3}{*}{$\begin{array}{l}\mathrm{Hg}^{+2} \\
\text { Removal } \\
\text { by FGD, } \\
\%\end{array}$} & \multirow{3}{*}{$\begin{array}{l}\mathrm{Hg}^{0} \\
\text { Removal } \\
\text { by FGD, } \\
\%\end{array}$} \\
\hline & & & $\mathrm{Hg}$ & $\mathrm{Hg}^{0}$ & $\mathrm{Hg}$ & $\mathrm{Hg}^{0}$ & & & & \\
\hline \multirow[t]{2}{*}{$4 / 25$} & Average & & 23.4 & 17.2 & 10.9 & 7.0 & & & & \\
\hline & Std. Dev. & - & 2.2 & 2.1 & 1.2 & 0.7 & - & - & - & - \\
\hline \multirow[t]{2}{*}{$4 / 26$} & Average & 5 & 19.8 & 8.9 & 9.9 & 5.8 & $55 \%$ & $50 \%$ & $62 \%$ & $35 \%$ \\
\hline & Std. Dev. & - & 3.9 & 1.5 & 3.6 & 0.6 & - & - & - & - \\
\hline \multirow[t]{2}{*}{$4 / 27$} & Average & 10 & 21.6 & 13.4 & 11.4 & 9.0 & $38 \%$ & $47 \%$ & $71 \%$ & $33 \%$ \\
\hline & Std. Dev. & - & 3.6 & 1.6 & 2.5 & 1.1 & - & - & - & - \\
\hline \multirow[t]{2}{*}{$4 / 28$} & Average & 20 & 17.9 & 10.1 & 9.6 & 7.3 & $44 \%$ & $47 \%$ & $71 \%$ & $28 \%$ \\
\hline & Std. Dev. & - & 7.4 & 0.8 & 3.8 & 2.5 & - & - & - & - \\
\hline \multirow[t]{2}{*}{$4 / 29$} & Average & 40 & 22.3 & 15.2 & 13.7 & 12.0 & $32 \%$ & $39 \%$ & $77 \%$ & $21 \%$ \\
\hline & Std. Dev. & - & 3.4 & 4.2 & 2.8 & 1.4 & - & - & - & - \\
\hline
\end{tabular}

With no measurable evidence of re-emissions to be controlled, the test objectives were focused on other expected effects of TMT-15 injection, including reduced FGD liquor mercury concentration and the ability to form mercury salts that can be inertially separated from the byproduct gypsum. Tests were conducted at the four TMT dosage rates described above.

The pilot FGD mercury removal data for the TMT tests are also included in Table 4. Although there was some day-to-day variability, the results did not indicate any significant effect of the additive on FGD capture of mercury; no effect was expected. As did the baseline test results from April $25^{\text {th }}$, the results for all four TMT dosage tests showed no evidence of mercury reemissions and, in fact, showed some removal of elemental mercury.

\section{Mercury Concentrations in FGD Liquor and Solids}

The effects of the additive on FGD liquor and byproduct gypsum mercury concentrations are shown in Figure 7 and Table 5 below, respectively. The FGD liquors were digested by EPA Method 7470 and analyzed by atomic fluorescence. The gypsum solids were digested by a modified version of EPA Method 3051 and also analyzed by atomic fluorescence. Results are shown as a function of TMT-15 dosage, in mL/ton of coal fired. 


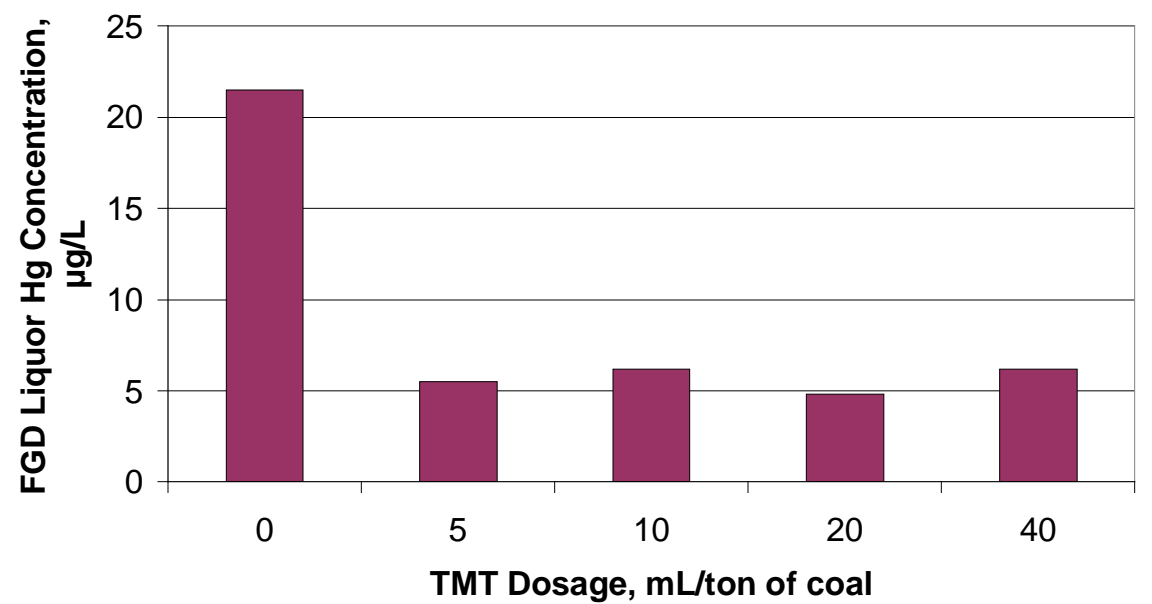

Figure 7. Effect of TMT Addition on FGD Liquor Total Hg Concentration, $\mu \mathrm{g} / \mathrm{L}$

Table 5. Effect of TMT Addition on FGD Gypsum Hg Concentrations

\begin{tabular}{|l|l|l|l|l|}
\hline $\begin{array}{l}\text { TMT Dosage } \\
(\mathbf{m L} / \text { ton of coal) }\end{array}$ & $\begin{array}{l}\text { Wt\% Gypsum } \\
\text { Phase in Slurry }\end{array}$ & $\begin{array}{l}\text { Gypsum } \mathbf{H g} \\
\text { Content, } \boldsymbol{\mu g} / \mathbf{g}(\% \text { of } \\
\mathbf{H g} \text { in slurry) }\end{array}$ & $\begin{array}{l}\text { Wt\% Fines } \\
\text { in Slurry }\end{array}$ & $\begin{array}{l}\text { Fines } \mathrm{Hg} \text { Content, } \\
\mathbf{s} / \mathbf{g}(\% \text { of } \mathrm{Hg} \text { in }\end{array}$ \\
\hline 0 & 11.6 & $1.7(53 \%)$ & 0.3 & $55(44 \%)$ \\
\hline 5 & 9.2 & $1.2(33 \%)$ & 0.5 & $39(65 \%)$ \\
\hline 10 & 10.7 & $1.2(36 \%)$ & 0.3 & $75(62 \%)$ \\
\hline 20 & 10.0 & $1.0(33 \%)$ & 0.4 & $52(63 \%)$ \\
\hline 40 & 9.3 & $1.2(36 \%)$ & 0.3 & $57(61 \%)$ \\
\hline
\end{tabular}

The liquor mercury concentration results in Figure 7 show that the addition of TMT-15 lowered the mercury concentration by approximately a factor of four, but there was no apparent dosage effect. That is, the lowest dosage was nominally as effective as the highest dosage tested.

The solids mercury concentration results shown in Table 5 require discussion. It was expected that adding TMT-15 would result in the formation of fine mercury-TMT salts that would be incorporated with the FGD solid byproducts, and that some form of physical separation would be required to separate the mercury-rich fine salts from the larger gypsum particles. While most LSFO FGD systems have hydrocyclones to dewater the byproduct slurry and separate fine solids, the pilot wet FGD system did not, at that time, include hydrocyclones for primary dewatering of the blow down slurry. Therefore, this separation had to be conducted in the laboratory, using gravity-based settling to allow the fines to be decanted from the rapidly settling and lighter colored gypsum solids. 
The results in Table 5 show that after fines separation, the gypsum mercury concentration was reduced in the TMT addition tests from $1.7 \mu \mathrm{g} / \mathrm{g}$ for the baseline (no TMT) byproduct from April 25 to 1.0 to $1.2 \mu \mathrm{g} / \mathrm{g}$ during TMT injection. Again, there was no apparent effect of TMT injection dosage on the result, indicating that a dosage even lower than $5 \mathrm{~mL} /$ ton of coal might have been adequate.

However, the reduction in gypsum mercury concentration of 30 to $40 \%$ seen with TMT addition was not as great as had been hoped. As can be seen in the data in Table 5, a small amount of fines was gravity separated from each slurry sample, and the fines contained a very high concentration of mercury. In the case of the TMT tests, the fines mercury content represented greater than $60 \%$ of the mercury content of the original FGD blow down slurry. Even a small contamination of the byproduct gypsum with fines could markedly increase its measured mercury concentration.

\section{FGD Solids Particle Size Analyses}

These solids samples were sent out for subsequent measurement of particle size distribution, using a Leco "Lecotrac" particle size analyzer on solids dispersed in methanol. The results of these particle size analyses are summarized in Table 6 . The results show that the settled gypsum phase had a mean particle size in the range of 40 to $45 \mu \mathrm{m}$, which is typical of gypsum sold for use in wallboard production. The fines have a much smaller particle size, with a mean of about $26 \mu \mathrm{m}$ for the baseline (no TMT) test on April 25, and an even lower mean in the range of 15 to $20 \mu \mathrm{m}$ for the TMT tests. Perhaps the formation of fine TMT-mercury salts tended to lower the mean particle size in the fines phase.

\section{Table 6. Results of Particle Size Analyses of Gravity Separated Solids from TMT Parametric Tests}

\begin{tabular}{|c|c|c|c|c|c|}
\hline Test Date & $\begin{array}{l}\text { TMT Dosage, } \\
\mathrm{mL} / \text { ton of coal }\end{array}$ & Sample & $\mathbf{D}_{10}{ }^{*}, \mu \mathrm{m}$ & $\mathbf{D}_{50}{ }^{*}, \mu \mathrm{m}$ & $\mathbf{D}_{90}{ }^{*}, \mu \mathrm{m}$ \\
\hline \multirow[t]{2}{*}{$4 / 25$} & \multirow[t]{2}{*}{0 (Baseline) } & Product Gypsum & 24.4 & 43.7 & 70.8 \\
\hline & & Fines & 7.7 & 26.0 & 37.7 \\
\hline \multirow[t]{2}{*}{$4 / 26$} & \multirow[t]{2}{*}{5} & Product Gypsum & 24.2 & 42.3 & 66.9 \\
\hline & & Fines & 2.9 & 14.9 & 30.6 \\
\hline \multirow[t]{2}{*}{$4 / 29$} & \multirow[t]{2}{*}{40} & Product Gypsum & 26.0 & 39.5 & 52.1 \\
\hline & & Fines & 6.0 & 19.4 & 29.7 \\
\hline
\end{tabular}

*Particle size at which $10 \%, 50 \%$, or $90 \%$ of the sample mass is smaller

Figure 8 illustrates the details of the particle size data, for the $5 \mathrm{~mL} /$ ton TMT additive test on April 26. The data show that although the two solids fractions have substantially different particle size distributions, there is a percentage of the gypsum phase that is in the same particle size range as the bulk of the fines phase $(\sim 14$ to $30 \mu \mathrm{m})$. Even percent-level mass in these 
particle size ranges could represent high mercury content fines that contribute significantly to the mercury content of the gypsum.

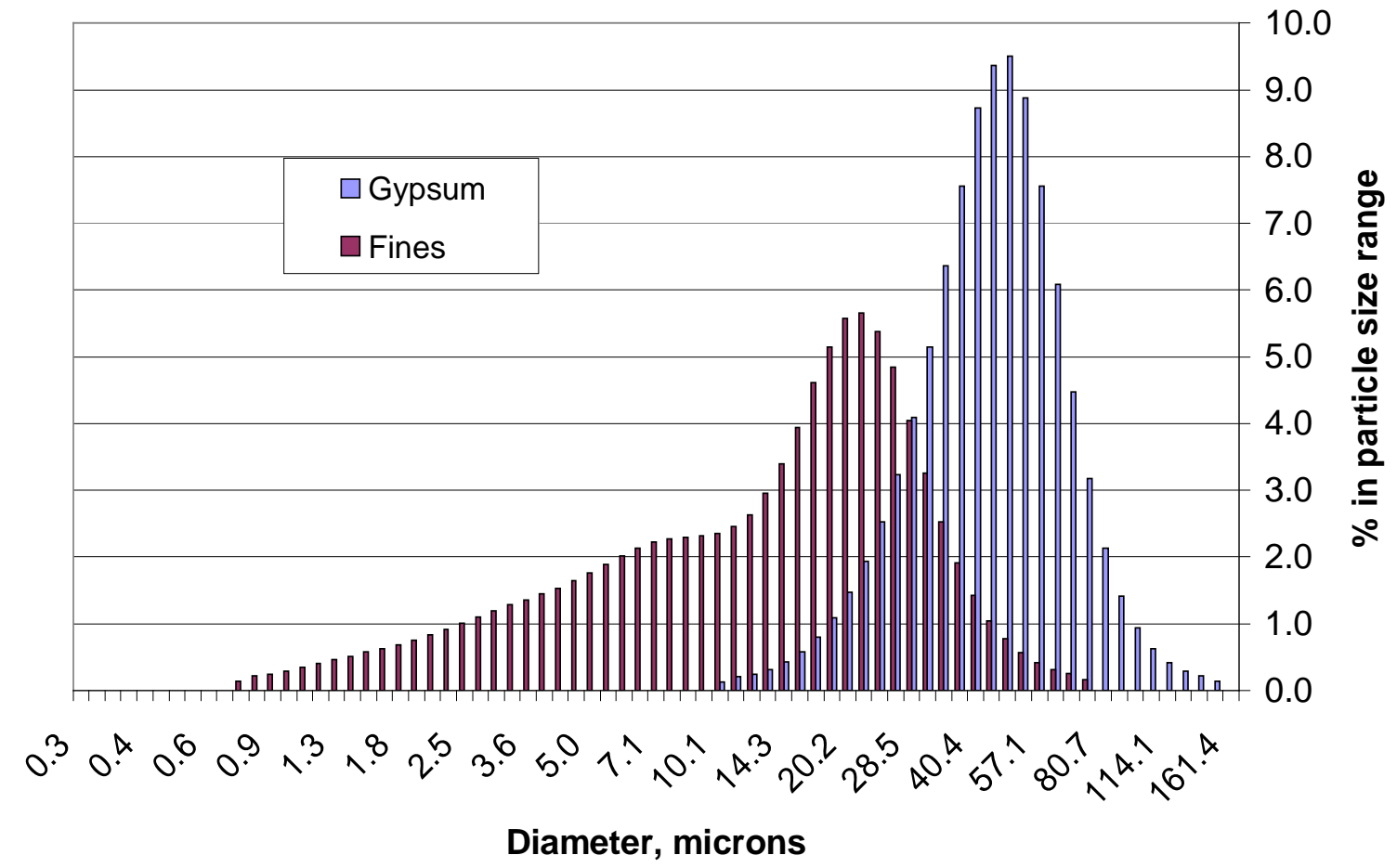

Figure 8. Comparison of Gypsum and Fines Particle Size Distributions for $5 \mathrm{~mL} /$ ton of coal TMT Additive Test

There was concern that gravity settling separation used in the laboratory may not have been as effective as hydrocyclones at separating fines from the bulk gypsum. Consequently, it was decided that for the subsequent steady-state TMT addition test, a hydrocyclone should be used to separate fines from the bulk gypsum in the field. EPRI funded the retrofit of a hydrocyclone to the pilot wet FGD system to provide for primary dewatering in the field. Follow-up TMT tests were conducted on the wet FGD pilot at Monticello in late September 2005 using this hydrocyclone to separate the fines from the bulk gypsum. The hydrocyclone was also used for primary dewatering of a slipstream of slurry from the pilot JBR test at Plant Yates. Results from that test are discussed later in this section.

\section{FGD Operating Conditions}

During the parametric tests, the reaction tank $\mathrm{pH}$ was typically controlled at a value of 5.7 to 5.8, and the reaction tank temperature was about 122 to $132^{\circ} \mathrm{F}$. The lower temperatures typically corresponded with times after make up of cool fresh water to the reaction tank. Oxidation reduction potential (ORP) was checked with a hand-held instrument, and typically ranged from 250 to $325 \mathrm{mV}$. SO $\mathrm{SO}_{2}$ removal was checked intermittently during the week with a Western Model $721 \mathrm{UV} \mathrm{SO}_{2}$ Analyzer. Although the data are not reported here, the spot checks ranged from $85 \%$ to $97 \% \mathrm{SO}_{2}$ removal across the FGD system, with no apparent correlation with TMT dosage. Inlet $\mathrm{SO}_{2}$ concentrations were around $300 \mathrm{ppmv}$ (dry basis) at as-measured $\mathrm{O}_{2}$ levels. 
Samples of the wet FGD pilot reaction tank slurry were collected and preserved daily to determine FGD operating conditions during these tests. The results of those analyses are summarized in Table 7 for the FGD slurry liquor samples and Table 8 for the FGD slurry solid chemical analyses. They show that for all test days, the FGD system was operating as a highly oxidized forced oxidation system ( $>97 \%$ gypsum as the solid byproduct) with very high limestone reagent utilization. The liquor analyses show that concentrations of major species such as calcium, chloride and sulfate were relatively constant over the test week, although the TMT additions tests were about 10 to $20 \%$ more dilute in soluble species than the baseline test on April 25.

Table 7. Results of FGD Liquor Sample Analyses for the TMT Parametric Tests (mg/L unless noted otherwise)

\begin{tabular}{|l|l|l|l|l|l|l|l|}
\hline TMT-15 Addition Rate (Date) & $\mathrm{SO}_{3}$ & $\mathbf{S O}_{4}$ & $\mathrm{Cl}^{-}$ & $\mathrm{Mg}$ & $\mathrm{Ca}$ & $\mathrm{Na}$ & $\mathbf{C O}_{3}$ \\
\hline Baseline [no TMT] (4/25) & $<8$ & 5,807 & 1,779 & 1,363 & 623 & 951 & 144 \\
\hline $5 \mathrm{~mL} /$ ton of coal (4/26) & $<8$ & 5,192 & 1,458 & 1,119 & 641 & 814 & 70 \\
\hline $10 \mathrm{~mL} /$ ton of coal (4/27) & $<8$ & 5,390 & 1,506 & 1,152 & 639 & 840 & 74 \\
\hline $20 \mathrm{~mL} /$ ton of coal (4/28) & $<8$ & 5,115 & 1,395 & 1,057 & 639 & 786 & 60 \\
\hline $40 \mathrm{~mL} /$ ton of coal (4/29) & $<8$ & 5,305 & 1,446 & 1,184 & 639 & 811 & 47 \\
\hline
\end{tabular}

Table 8. Results of FGD Solid Sample Analyses for the TMT Parametric Tests (mg/g unless noted otherwise)

\begin{tabular}{|c|c|c|c|c|c|c|c|c|}
\hline \multirow[b]{2}{*}{ TMT-15 Addition Rate (Date) } & \multirow{2}{*}{$\begin{array}{l}\text { Slurry } \\
\text { Wt\% } \\
\text { Solids }\end{array}$} & \multirow{2}{*}{$\begin{array}{l}\text { Solids } \\
\text { Wt\% } \\
\text { Inerts* }\end{array}$} & \multicolumn{5}{|c|}{ Solids Analysis, mg/g } & \multirow{2}{*}{$\begin{array}{l}\text { Solids } \\
\text { Wt\% } \\
\text { Gypsum }\end{array}$} \\
\hline & & & $\mathrm{Ca}$ & Mg & $\mathrm{SO}_{4}$ & $\mathrm{SO}_{3}$ & $\mathrm{CO}_{3}$ & \\
\hline Baseline [no TMT] (4/25) & 13.2 & 1.33 & 225 & $<1$ & 544 & $<1$ & 2 & 97.4 \\
\hline $5 \mathrm{~mL} /$ ton of coal $(4 / 26)$ & 11.9 & 1.21 & 229 & $<1$ & 549 & $<1$ & 3 & 98.3 \\
\hline $10 \mathrm{~mL} /$ ton of coal $(4 / 27)$ & 12.2 & 0.99 & 232 & $<1$ & 550 & $<1$ & 3 & 98.5 \\
\hline $20 \mathrm{~mL} /$ ton of coal $(4 / 28)$ & 11.6 & 0.85 & 230 & $<1$ & 556 & $<1$ & 2 & 99.6 \\
\hline $40 \mathrm{~mL} /$ ton of coal (4/29) & 10.2 & 0.99 & 230 & $<1$ & 552 & $<1$ & 2 & 98.6 \\
\hline
\end{tabular}

*Inerts are acid-insoluble solids that can include fly ash and mineral impurities from the limestone reagent

\section{Steady-State Test Results}

As described above, the steady-state TMT additive test at Monticello was delayed until the last week of September to allow time to specify, procure and set up a primary dewatering system to size separate the solids in the slurry blow down from the pilot wet FGD system. 
Note that throughout this report the term "blow down" is used to describe the slurry fed to the hydrocyclone for dewatering. However, because the FGD system uses a slurry pump to continuously recirculate slurry from the reaction tank through the absorber and the blow down is a slipstream of that recirculating slurry, the blow down is identical to the reaction tank slurry. Also in this report, the term "fines" is used to describe the solids in the hydrocyclone overflow, while the term "byproduct gypsum" is used to describe the solids in the hydrocyclone underflow. In most LSFO FGD systems, the hydrocyclone underflow becomes the feed to the vacuum filter for secondary dewatering, and thus is the source of the gypsum byproduct.

In the original project plan, there was no need to conduct a baseline (no TMT addition) test during this second week of testing, as it was to have followed a weeklong parametric test effort that included a baseline test. However, because five months elapsed between the two weeks of TMT additive testing, a baseline (no TMT) test was conducted during the first part of the second week to measure mercury removal across the pilot FGD system with no TMT additive.

Also, the steady-state TMT additive test was conducted downstream of a gold-based mercury oxidation catalyst, whereas the previous parametric tests were conducted with no oxidation catalyst upstream. This change resulted in a higher percentage of oxidized mercury (rather than elemental mercury) in the FGD inlet flue gas for the steady-state test. The reason for conducting this test downstream of the gold catalyst was based on previous results from pilot wet FGD tests conducted downstream of four mercury oxidation catalysts being tested at Monticello as part of the NETL co-funded 41992 project. Those results showed significant mercury re-emissions when scrubbing the flue gas from downstream of the gold catalyst. ${ }^{2}$ It was expected that conducting the TMT-15 steady-state test downstream of the gold catalyst would provide an opportunity to observe the effectiveness of TMT in preventing mercury re-emissions.

The steady-state TMT additive test was conducted at a TMT-15 dosage of $20 \mathrm{~mL} /$ ton of coal fired. Although the parametric tests conducted earlier at Monticello showed virtually no effect of TMT-15 dosage over the range of 5 to $40 \mathrm{~mL} /$ ton of coal on FGD liquor mercury concentrations, it was decided to go with the higher dosage of $20 \mathrm{~mL} /$ ton for two reasons. One was concern that since this test was to be conducted downstream of the gold mercury oxidation catalyst, it might take a higher TMT dosage than in the parametric tests because of higher expected oxidized mercury concentrations in the FGD inlet flue gas. The other reason was that $20 \mathrm{~mL} /$ ton coincides with Degussa's "rule of thumb" for required TMT dosage to minimize mercury re-emissions, and it was felt that it would be best to test at their recommended dosage, rather than a lower dosage that might later prove to be less effective.

\section{Mercury Removal Data}

Two mercury SCEMs were used to monitor mercury capture across the wet FGD during baseline operation (no TMT addition) and during TMT-15 addition. Unfortunately, the SCEM used to track FGD inlet mercury concentrations suffered a hard drive failure in the computer used to control analyzer operation and record analyzer results. This hard drive failure resulted in a complete loss of the inlet analyzer data up through the last day of the steady-state TMT-15 test. Although some raw data were recorded in a notebook by the SCEM operator as the data were produced, the data recorded were not complete enough to recreate the lost electronic data. 
The flue gas at Monticello changes markedly in total mercury concentration and mercury speciation due to temporal variations in fuel quality, and variations in the percentage of lignite versus PRB fired in the unit. For this reason, FGD outlet data alone, which were not lost, are of little value in measuring mercury removal by species across the FGD system. On the last day of the steady-state test, the single remaining SCEM was cycled between analyzing the FGD inlet and outlet flue gases, and between measuring total and elemental mercury concentrations at each location. Again, because of significant temporal variations in mercury concentrations and oxidation percentage at Monticello, these single analyzer cycling data are of little use in quantifying FGD removal of mercury species. Since the SCEM data are of little use, they are not included in this report.

Fortunately, as planned, triplicate Ontario Hydro measurements were made at the FGD inlet and outlet on the last day of the TMT-15 steady-state test. These data provide information about mercury capture and re-emission levels across the pilot wet FGD system during the TMT-15 steady state tests. Previous "baseline condition" (no TMT) data are available from operation of the wet FGD pilot unit downstream of the gold catalyst in April 2005 as part of the NETL cofunded 41992 project. Results from both sets of Ontario Hydro measurements are shown in Table 9.

Table 9. Results of Ontario Hydro Method Measurements Across Wet FGD Pilot Unit for Operation Downstream of Gold Catalyst - with and without TMT-15 Addition (mean value for three runs \pm the $95 \%$ confidence interval about the mean)

\begin{tabular}{|c|c|c|c|c|c|}
\hline & \multicolumn{2}{|c|}{$\begin{array}{l}\mathrm{Hg} \text { Concentration }\left(\mu \mathrm{g} / \mathrm{Nm}^{3} @\right. \\
\left.3 \% \mathrm{O}_{2}\right)^{*}\end{array}$} & \multirow{2}{*}{$\begin{array}{l}\text { Total } \mathrm{Hg} \\
\text { Oxidation at } \\
\text { FGD Inlet (\%) }\end{array}$} & \multirow{2}{*}{$\begin{array}{l}\text { Hg Removal } \\
\text { Across FGD } \\
\text { (\%) }\end{array}$} & \multirow{2}{*}{$\begin{array}{l}\mathrm{Hg} \mathrm{Re}- \\
\text { emissions (\% } \\
\text { of inlet } \mathrm{Hg}^{+2} \text { ) }\end{array}$} \\
\hline & FGD Inlet & FGD Outlet & & & \\
\hline \multicolumn{6}{|c|}{ April 20, 2005 Baseline (no TMT addition) Results: } \\
\hline $\mathrm{Hg}^{+2}$ & $28.3 \pm 2.3$ & $3.8 \pm 0.9$ & - & $87 \pm 3$ & - \\
\hline $\mathrm{Hg}^{0}$ & $1.1 \pm 0.2$ & $3.2 \pm 1.7$ & - & $-189 \pm 95$ & $7.5 \pm 2.7$ \\
\hline Total Hg & $29.4 \pm 2.5$ & $7.0 \pm 2.7$ & $96 \pm 1$ & $76 \pm 4$ & - \\
\hline \multicolumn{6}{|c|}{ September 29-30, 2005 Steady-state TMT-15 Test Results (20 mL/ton of coal): } \\
\hline $\mathrm{Hg}^{+2}$ & $7.06 \pm 0.55$ & $0.17 \pm 0.04$ & - & $98 \pm 1$ & - \\
\hline $\mathrm{Hg}^{0}$ & $3.45 \pm 0.40$ & $3.98 \pm 0.43$ & - & $-15 \pm 17$ & $7.5 \pm 8.4$ \\
\hline Total Hg & $10.5 \pm 0.8$ & $4.15 \pm 0.47$ & $67 \pm 2$ & $61 \pm 7$ & - \\
\hline
\end{tabular}

*Note: $1 \mu \mathrm{g} / \mathrm{Nm}^{3} @ 3 \% \mathrm{O}_{2}=0.67 \mathrm{lb}$ of $\mathrm{Hg}$ per $10^{12}$ Btu heat input

There are several things to note about the results shown in Table 9. One is that comparing April and September data, the FGD inlet total mercury concentrations are quite a bit different. The total in September is only about $36 \%$ of the April concentration. This suggests that in September, 
the unit was firing a higher percentage of PRB coal (which has a lower mercury content than the Texas lignite) than in April, and/or that the fuels being fired had a lower mercury content.

Mercury analyses on the PRB and lignite fired during the April and September tests suggest that both of these affected in the FGD inlet total mercury concentration. Table 10 summarizes PRB and lignite sample mercury concentrations for the days corresponding to the two Ontario Hydro measurement periods.

Table 10. Results of PRB Coal and Lignite Mercury Concentration Analyses

\begin{tabular}{|l|l|l|}
\hline & $\begin{array}{l}\text { Hg in Texas Lignite Sample } \\
(\mu \mathbf{g} / \mathbf{g})\end{array}$ & Hg in PRB Sample $(\mu \mathbf{g} / \mathbf{g})$ \\
\hline April 18, 2005 & 0.312 & 0.092 \\
\hline April 19, 2005 & 0.329 & 0.126 \\
\hline April 20, 2005 & 0.269 & 0.083 \\
\hline September 28, 2005 & 0.363 & 0.059 \\
\hline September 29, 2005 & 0.370 & 0.053 \\
\hline September 30, 2005 & 0.265 & 0.040 \\
\hline
\end{tabular}

The mercury concentrations in the Texas lignite samples were similar in April and September, but the mercury concentrations in the PRB samples were considerably lower in September than in April. The lower mercury concentrations in the PRB fuel could not alone account for the FGD inlet total mercury being almost a factor of three lower in September than in April. However, the PRB mercury content is nearly an order of magnitude lower than in the lignite on a mass per Btu basis. So, firing a higher percentage of the lower-mercury-content PRB in September compared to the amount fired in April could readily explain the observed difference in total flue gas mercury concentration. Although SCEM results from September were not presented in this report, the limited amount of FGD inlet data from the SCEM prior to its hard drive failure confirm that FGD inlet total mercury concentrations were in the range of 10 to $15 \mu \mathrm{g} / \mathrm{Nm}^{3} @ 3 \%$ $\mathrm{O}_{2}$, which agrees with the Ontario Hydro method results.

Another thing to note in Table 9 is that the effectiveness of the gold catalyst at oxidizing elemental mercury in the FGD inlet flue gas was significantly lower in September than in April. The data show $96 \%$ total mercury oxidation at the FGD inlet in April, but only $67 \%$ in September. This is believed to be due to a buildup of fly ash in the horizontal gas flow channels of the catalyst, caused by malfunctions of the sonic horns that are meant to prevent fly ash buildup. As a result of these differences between total mercury concentration and oxidation percentage between the April and September data, the FGD inlet oxidized mercury concentration in September was only $25 \%$ of the April concentration.

The September data show considerably higher apparent percent removal of oxidized mercury than was measured in April, 98\% versus 87\%, respectively. The lower percentage in April is 
believed to be due to a mechanical problem (slurry recirculation pump cavitation) that lowered the FGD absorber liquid-to-gas ratio during the April test. The apparent improvement in September is believed to be due to correcting the cavitation problem and not related to TMT addition.

The September data show considerably less mercury re-emissions across the wet FGD absorber than in April, when expressed in terms of the increase in elemental mercury concentration across the absorber. This is an expected benefit of TMT addition. In the April data, the elemental mercury concentration increase across the wet FGD pilot was measured to be $2.1 \mu \mathrm{g} / \mathrm{Nm}^{3} @ 3 \%$ $\mathrm{O}_{2}$ (3.2 minus 1.1) whereas in September the increase was only $0.5 \mu \mathrm{g} / \mathrm{Nm}^{3} @ 3 \% \mathrm{O}_{2}$.

Furthermore, when the $95 \%$ confidence intervals of the September data are considered, the mean concentrations of elemental mercury at the FGD inlet and outlet overlap substantially, meaning it was not certain that any re-emissions were occurring during the September TMT test. As an example, the mean inlet elemental mercury concentration plus one $95 \%$ confidence interval ranges from 3.45 to $3.85 \mu \mathrm{g} / \mathrm{Nm}^{3}$ @ 3\% $\mathrm{O}_{2}$, while the mean outlet concentration minus one $95 \%$ confidence interval ranges from 3.55 to $3.98 \mu \mathrm{g} / \mathrm{Nm}^{3} @ 3 \% \mathrm{O}_{2}$. These ranges are almost identical, meaning there is a reasonable probability that the inlet and outlet elemental mercury concentrations were identical and there were no re-emissions during this test. This view of the data suggests that the TMT-15 addition was effective at reducing or eliminating re-emissions when operating the FGD system downstream of the gold catalyst.

However, the re-emissions level can also be expressed as a percentage of the FGD inlet oxidized mercury. This seems like a relevant way of expressing the re-emissions rate since it is the oxidized mercury that is absorbed and chemically reduced to produce re-emissions, and reemissions levels might be expected to be a function of the amount of oxidized mercury absorbed. Because the FGD inlet oxidized mercury concentration in September was only $25 \%$ of that in April, when the re-emissions are calculated as a percentage of the inlet oxidized mercury concentration, the mean re-emission percentages are identical for the April and September data, at $7.5 \%$.

This might call into question the effectiveness of TMT-15 in limiting re-emissions, except that the $95 \%$ confidence interval for the mean re-emissions percentage from the September data is greater than the actual mean $(8.4 \%$ versus a mean of $7.5 \%)$. This means the $95 \%$ confidence interval of the data includes zero re-emissions or less, so there is no certainty that re-emissions were actually occurring during the September measurements.

It should be noted that measurement of mercury re-emissions can be difficult, as it requires the simultaneous measurement of elemental mercury concentrations in both the FGD inlet and outlet flue gases. Re-emissions are quantified as the difference between the two values. If the reemissions levels are relatively small, this measurement is prone to error because it is quantified by subtracting one large number from another to quantify a small difference. The relative standard deviation for the Ontario Hydro method is cited as less than $11 \%$ for mercury concentrations greater than $3 \mu \mathrm{g} / \mathrm{Nm}^{3}$ and less than $34 \%$ for concentrations less than $3 \mu \mathrm{g} / \mathrm{Nm}^{3}{ }^{3}$. It is obvious that subtracting two values with these level of relative standard deviation possible can lead to errors in quantifying the difference. Furthermore, the FGD outlet location is difficult for measuring mercury concentrations, because the flue gas is wet and can contain entrained 
FGD liquor droplet carryover. These droplets can contain absorbed mercury and can bias measurement results.

In summary, the Ontario Hydro data are not conclusive about the effectiveness of TMT-15 in limiting re-emissions from the pilot wet FGD system when operating downstream of the gold mercury oxidation catalyst. Uncertainty in the mean quantity of re-emissions measured by the Ontario Hydro method limits the conclusions that can be made from these data.

\section{Mercury Concentrations in FGD Liquor and Solids}

During the September tests, samples were collected and preserved of the FGD blow down slurry liquor and solids. These samples were analyzed to determine the effects of TMT addition on mercury concentrations in the slurry liquor and solids. The results of these analyses are shown in Table 11 below.

Table 11. FGD Blow Down Slurry Liquor and Solids Mercury Concentrations (solids concentrations based on samples filtered on site)

\begin{tabular}{|c|c|c|c|c|}
\hline Sample & $\begin{array}{l}\text { Liquor } \mathrm{Hg} \\
\text { Concentration } \\
(\mu \mathrm{g} / \mathrm{L})\end{array}$ & $\begin{array}{l}\text { Wt\% } \\
\text { Solids }\end{array}$ & $\begin{array}{l}\text { Solids } \mathrm{Hg} \\
\text { Concentration } \\
(\mu \mathrm{g} / \mathrm{g})\end{array}$ & $\begin{array}{l}\text { \% of FGD Blow } \\
\text { Down Hg in Slurry } \\
\text { Found in Liquor } \\
\text { (calculated value) }\end{array}$ \\
\hline \multicolumn{5}{|c|}{ Baseline [no TMT] (9/28/05): } \\
\hline FGD Blow Down Slurry & 32.2 & 13.2 & 1.63 & 11.5 \\
\hline Hydrocyclone Overflow & 19.4 & $13.2^{*}$ & 1.94 & - \\
\hline Hydrocyclone Underflow & 15.0 & 62.1 & 3.02 & - \\
\hline \multicolumn{5}{|c|}{ TMT-15 at $20 \mathrm{~mL} /$ ton of coal $(9 / 29 / 05)$ : } \\
\hline FGD Blow Down Slurry & 3.54 & 11.9 & 3.64 & 0.7 \\
\hline Hydrocyclone Overflow & 3.34 & 3.3 & 6.47 & - \\
\hline Hydrocyclone Underflow & 3.84 & 62.7 & 0.64 & - \\
\hline \multicolumn{5}{|c|}{ TMT-15 at $20 \mathrm{~mL} /$ ton of coal $(9 / 30 / 05)$ : } \\
\hline FGD Blow Down Slurry & 2.77 & 12.2 & 5.17 & 0.4 \\
\hline Hydrocyclone Overflow & 1.90 & 4.1 & 7.02 & - \\
\hline Hydrocyclone Underflow & 2.56 & 64.1 & 1.01 & - \\
\hline
\end{tabular}

*It appears that the sample analyzed for wt $\%$ solids was a mislabeled FGD blow down slurry sample, since the wt $\%$ solids values are identical. For later mass balance calculations, a value of $4 \mathrm{wt} \%$ was assumed.

The results show that the FGD liquor mercury concentrations were reduced by over an order of magnitude by TMT-15 addition, comparing the baseline (no TMT) concentration from 
September 28 to the concentration during the second day of the steady-state test (32.2 versus $2.77 \mu \mathrm{g} / \mathrm{L}$ ). Correspondingly, the FGD blow down slurry solids mercury concentration increased with the addition of TMT, as would be expected.

The data in the far right column of Table 11 show the mercury in the FGD liquor as a percentage of the total amount of mercury in the slurry. This percentage was calculated from the data in the three columns to the left in the table. TMT-15 addition at $20 \mathrm{~mL} /$ ton of coal fired was observed to lower this percentage from $11.5 \%$ in the baseline test on September 28 to less than $0.5 \%$ by September 30 . Virtually all of the mercury absorbed by the FGD absorber was precipitated into the solid phase.

Also shown are liquor and solids mercury analyses on overflow and underflow samples after the FGD slurry blow down was sent through the hydrocyclone for primary dewatering. The expected result was that the FGD liquor mercury concentrations would be approximately the same as in the blow down slurry, as the liquor should be homogenous, but that the solids mercury concentrations would be markedly different between the overflow and underflow. This is because previous results from a variety of sites have shown that gypsum fines tend to be much richer in mercury than the larger gypsum byproduct solids.

Furthermore, most of the solids in the blow down slurry should report to the underflow, while most of the liquor should report to the overflow. Thus, the overflow should have a lower wt $\%$ solids concentration than the blow down slurry and a higher solids mercury concentration, while the underflow should have a higher wt $\%$ solids but a lower solids mercury concentration than the blow down slurry.

The liquor mercury concentration results are as expected for the days where TMT was being added - the scrubber blow down, hydrocyclone overflow and underflow liquor samples all have similar mercury concentrations. However, for the baseline (no TMT) test on September 28, the hydrocyclone overflow and underflow liquor samples show lower mercury concentrations than the blow down slurry. This may be a residence time effect, as data from other sites has shown that liquid phase mercury concentrations tend to decrease after slurries leave the FGD absorber reaction tank, presumably due to adsorption on the solids in the slurry over time. The order in which these samples were filtered and preserved after they were collected may have impacted how much mercury remained with the liquor.

The solids show the expected effect of the hydrocyclone with respect to wt\% solids - with the exception of the one value footnoted in the table. Otherwise, the hydrocyclone overflow samples show lower wt\% solids than the blow down slurry (hydrocyclone feed) while the underflow samples show much higher wt $\%$ solids. However, with respect to solids mercury concentrations, only the samples from the two TMT addition test days show the expected trend, where the hydrocyclone overflow solids have a higher mercury concentration than the FGD blow down solids, and the hydrocyclone underflow solids (gypsum byproduct) have a lower concentration. In the baseline sample set from September 28, the hydrocyclone underflow (gypsum byproduct) sample has a higher concentration than either the feed (FGD blow down) or overflow from the hydrocyclone, rather than a lower concentration as expected. It seems unlikely that both the 
hydrocyclone overflow and underflow solids could have a higher mercury concentration than the feed, so these results are obviously anomalous.

After reviewing these data, it was theorized that a bias was introduced when the samples were filtered and preserved on site. The sampling and preservation technique used at the time was to collect a sample of about $500 \mathrm{~mL}$ in volume, then filter a portion on site to recover a preserved liquor and solid aliquot. While filtering a portion of the sample should produce a representative liquor sample, it may bias the solid sample. It has been shown that FGD solids mercury concentrations vary significantly with particle size, with mercury concentrations being much higher in the fine particles. The sample particle size distribution data discussed below show that all samples had a significant percentage of fine particles. If only a portion of the sample is filtered, it is possible that some of the sample aliquots have had an over-represented fine particle fraction, and thus a high bias in the sample mercury concentration. Others may have an underrepresented fine particle fraction and a low bias in measured mercury concentration.

The current procedure is to collect smaller sample volumes and filter the entire amount of sample to collect representative solids. During the September tests, additional slurry samples were collected that were not filtered on site. These samples were subsequently filtered off site and analyzed for mercury concentration in an attempt to resolve these apparent anomalies. Normally, a slurry sample that has been allowed to sit for some time before filtering, as were these additional slurry samples, would tend to bias the solids mercury concentration high because of adsorption of mercury from the liquor in the slurry. However, particularly for the samples from the TMT test period, the liquor mercury represented such a small percentage of the total slurry mercury content that any such bias should be negligible.

The results of the mercury analyses on the solids from the slurries filtered off site are shown in Table 12, along with the original FGD liquor sample analyses on the aliquots filtered on site. The format of Table 12 is the same as Table 11 except that the alternate solid sample mercury values are shown.

The solids analysis results in Table 12, from the slurry samples filtered off site, better reflect the expected trends from these tests. The FGD blow down slurry solids mercury concentration increases from baseline through the second day of TMT addition, an expected result of TMT addition that reflects the higher percentage of the mercury in the slurry being found in the solid phase. Furthermore, the hydrocyclone overflow solids mercury concentrations were observed to increase with TMT addition, while the underflow solids mercury concentrations were observed to decrease. This is an expected effect of TMT to concentrate the mercury in the slurry in fine TMT salts. For all three days, the hydrocyclone overflow solids mercury concentration is higher than the blow down slurry solids concentration, while the underflow solids concentration is lower. This is expected because the fines are typically observed to have higher mercury concentrations than the larger gypsum particles, with or without TMT addition. Given that these new solids sample analyses better show expected trends, it is believed that the results shown in Table 12 better represent test results than the original data shown in Table 11, that were based on solids samples recovered on site with a partial slurry sample filtering technique. 
Table 12. FGD Blow Down Slurry Liquor and Solids Mercury Concentrations (solids concentrations based on samples filtered off site)

\begin{tabular}{|c|c|c|c|c|}
\hline Sample & $\begin{array}{l}\text { Liquor } \mathrm{Hg} \\
\text { Concentration } \\
(\mu \mathrm{g} / \mathrm{L})\end{array}$ & $\begin{array}{l}\text { Wt\% } \\
\text { Solids }\end{array}$ & $\begin{array}{l}\text { Solids } \mathrm{Hg} \\
\text { Concentration } \\
(\mu \mathrm{g} / \mathrm{g})\end{array}$ & $\begin{array}{l}\text { \% of FGD Blow } \\
\text { Down Hg in Slurry } \\
\text { Found in Liquor } \\
\text { (calculated value) }\end{array}$ \\
\hline \multicolumn{5}{|c|}{ Baseline [no TMT] (9/28/05): } \\
\hline FGD Blow Down Slurry & 32.2 & 13.2 & 1.42 & 13.0 \\
\hline Hydrocyclone Overflow & 19.4 & $13.2^{*}$ & 1.52 & - \\
\hline Hydrocyclone Underflow & 15.0 & 62.1 & 0.55 & - \\
\hline \multicolumn{5}{|c|}{ TMT-15 at $20 \mathrm{~mL} /$ ton of coal (9/29/05): } \\
\hline FGD Blow Down Slurry & 3.54 & 11.9 & 1.43 & 1.8 \\
\hline Hydrocyclone Overflow & 3.34 & 3.3 & 3.76 & - \\
\hline Hydrocyclone Underflow & 3.84 & 62.7 & 0.54 & - \\
\hline \multicolumn{5}{|c|}{ TMT-15 at $20 \mathrm{~mL} /$ ton of coal (9/30/05): } \\
\hline FGD Blow Down Slurry & 2.77 & 12.2 & 1.91 & 1.0 \\
\hline Hydrocyclone Overflow & 1.90 & 4.1 & 4.61 & - \\
\hline Hydrocyclone Underflow & 2.56 & 64.1 & 0.46 & - \\
\hline
\end{tabular}

*It appears that the sample analyzed for wt\% solids was a mislabeled FGD blow down slurry sample, since the wt $\%$ solids values are identical. For later mass balance calculations, a value of $4 \mathrm{wt} \%$ was assumed.

A comparison of the baseline (no TMT) test samples from September 28 with those from the second day of the steady-state TMT test shows that expected benefits of TMT addition were realized. The FGD liquor mercury concentrations were reduced by more than an order of magnitude, and the mercury concentration of the product gypsum (after fines removal) was reduced by a small margin (about 17\%). With TMT addition, most of the mercury in the slurry was concentrated in the fine particles found in the hydrocyclone overflow stream. However, the use of TMT-15 to precipitate mercury as a fine salt and the use of a hydrocyclone to separate those fine salts did not result in a gypsum byproduct completely free of mercury. This is further discussed below with the FGD solids particle size analysis results.

\section{FGD Solids Particle Size Analyses}

Samples of the FGD blow down (hydrocyclone feed), hydrocyclone overflow and underflow were sent out for particle size analyses by the same technique used for the parametric tests. The results of those particle size analyses are summarized in Table 13. The particle size analyses all show the expected trend, that the hydrocyclone overflow solids are finer than the FGD blow down solids (hydrocyclone feed) while the underflow solids are coarser. 
Table 13. Summary of Particle Size Analyses on Solid Samples from Steady-state TMT Additive Test

\begin{tabular}{|c|c|c|c|c|c|}
\hline $\begin{array}{l}\text { Test } \\
\text { Date }\end{array}$ & $\begin{array}{l}\text { TMT Dosage, } \\
\mathrm{mL} / \text { ton of coal }\end{array}$ & Sample & $\mathbf{D}_{10}{ }^{*}, \mu \mathrm{m}$ & $\mathbf{D}_{50}{ }^{*}, \mu \mathrm{m}$ & $\mathbf{D}_{90}{ }^{*}, \mu \mathrm{m}$ \\
\hline \multirow[t]{3}{*}{$9 / 28$} & \multirow[t]{3}{*}{0 (Baseline) } & Scrubber Blow Down & 19.6 & 46.2 & 73.0 \\
\hline & & Fines (HC Overflow) & 17.5 & 44.1 & 69.9 \\
\hline & & Product Gypsum (HC Underflow) & 34.3 & 55.7 & 85.6 \\
\hline \multirow[t]{3}{*}{$9 / 29$} & \multirow[t]{3}{*}{20} & Scrubber Blow Down & 16.4 & 39.9 & 64.6 \\
\hline & & Fines (HC Overflow) & 12.5 & 30.1 & 54.2 \\
\hline & & Product Gypsum (HC Underflow) & 34.7 & 53.9 & 80.8 \\
\hline \multirow[t]{3}{*}{$9 / 30$} & \multirow[t]{3}{*}{20} & Scrubber Blow Down & 18.9 & 39.3 & 63.6 \\
\hline & & Fines (HC Overflow) & 13.8 & 30.8 & 52.4 \\
\hline & & Product Gypsum (HC Underflow) & 29.3 & 48.5 & 74.1 \\
\hline
\end{tabular}

*Particle size at which $10 \%, 50 \%$, or $90 \%$ of the sample mass is smaller

These data also show that there is quite a bit of overlap in the particle size distributions of the hydroclone overflow and underflow. Hydrocyclones typically do not make a sharp separation at a given particle size, but instead tend to produce two streams with overlapping "bell shaped" particle size distributions. For example, for the September 30 samples, the $\mathrm{D}_{10}$ for the product gypsum was $29.3 \mu \mathrm{m}$, while the $\mathrm{D}_{50}$ for the fines was slightly coarser at $30.8 \mu \mathrm{m}$. This says that more than $10 \%$ of the product gypsum was finer than the median particle size of the fines. Since the fines sample from September 30 had a considerably higher mercury concentration than the product gypsum (see Table 12), it is likely that the fine particles that remain in the product gypsum account for most of its mercury content.

This concept is further illustrated in Figure 9 below, which compares the particle size distributions of the FGD blow down solids (hydrocyclone feed) to the product gypsum solids. The data are plotted as cumulative percent smaller than the particle diameters shown on the $\mathrm{X}$ axis. The plot shows that the FGD blow down slurry solids have a higher percentage of fine particles than the hydrocyclone underflow solids. This is expected, as the difference represents the fines removed in the hydrocyclone overflow. However, the figure also shows that $10 \%$ of the hydrocyclone underflow consists of particles smaller than $30 \mu \mathrm{m}$ in diameter, which most likely have a higher mercury concentration than the remaining $90 \%$ of the particles larger than $30 \mu \mathrm{m}$.

These data suggest that if hydrocyclones are used to separate fine TMT-mercury salts from the product gypsum, they will never be completely effective in removing all of the high-mercurycontent fine solids from the gypsum. Perhaps another size separation technique that can provide a sharper size cut, such as wet sieving, would be more effective. 


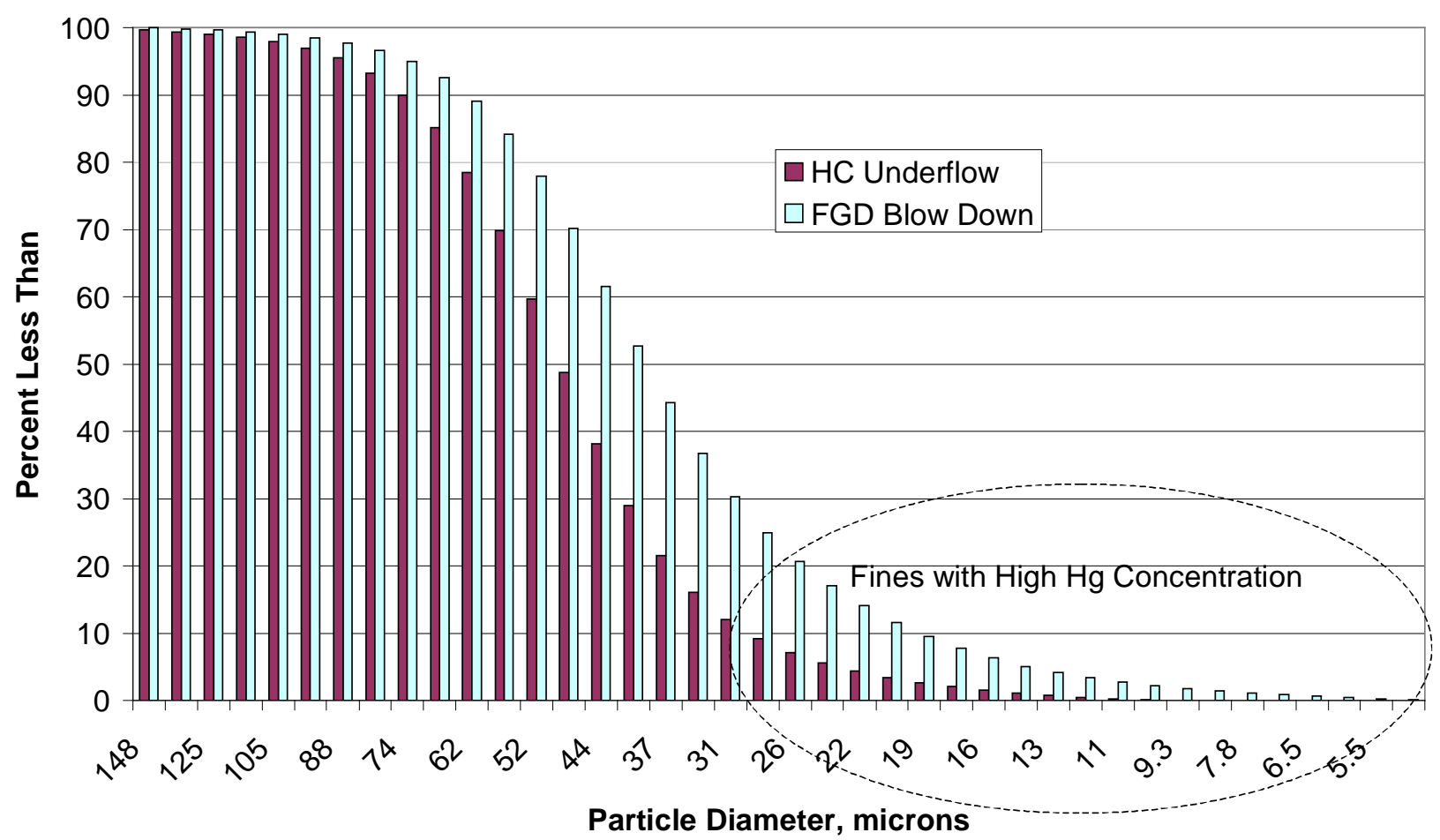

Figure 9. Comparison of Particle Size Distribution Data from 9/30/05

\section{FGD Operating Conditions}

During the September steady state test, the pilot FGD system operated around the clock (other than a couple of brief outages) from the afternoon of September 27 through the afternoon of September 30. The reaction tank $\mathrm{pH}$ was controlled at a value of 5.8, and the reaction tank temperatures ranged from 116 to $122^{\circ} \mathrm{F}$. Oxidation reduction potential (ORP) was not measured because of a problem with the hand-held instrument which was discovered after testing was underway.

$\mathrm{SO}_{2}$ removal was checked intermittently during the week with a Western Model $721 \mathrm{SO}_{2}$ Analyzer. Although the data are not reported here, the spot checks typically showed greater than $90 \% \mathrm{SO}_{2}$ removal across the FGD system, both during baseline operation on September 28 and during TMT addition the remainder of the week. As discussed later with the mass balance calculations, the average $\mathrm{SO}_{2}$ removal during the last day of the TMT addition period was slightly above $95 \%$.

Initial operation began by filling the pilot FGD reaction tank with slurry blow down from the Unit 3 full-scale FGD system. Samples of the wet FGD pilot reaction tank slurry were collected and preserved daily starting September 28 (after more than 24 hours of pilot FGD operation) to determine FGD operating conditions during these tests. The results of those analyses are summarized in Table 14 for the FGD slurry liquor samples and Table 15 for the FGD slurry solid chemical analyses. They show that for all test days, the FGD system was operating as a highly 
oxidized forced oxidation system ( $\geq 95 \%$ gypsum as the solid byproduct) with very high limestone reagent utilization.

Table 14. Results of FGD Liquor Sample Analyses for the TMT Steady State Test (mg/L unless noted otherwise)

\begin{tabular}{|c|c|c|c|c|c|c|c|c|c|}
\hline TMT-15 Addition Rate (Date) & $\mathbf{p H}$ & $\begin{array}{l}\text { Temp. } \\
{ }^{\circ} \mathrm{F}\end{array}$ & $\mathrm{SO}_{3}$ & $\mathrm{SO}_{4}$ & $\mathrm{Cl}^{-}$ & Mg & Ca & $\mathrm{Na}$ & $\mathrm{CO}_{3}$ \\
\hline Baseline [no TMT] (9/28) & 5.91 & 121 & $<1$ & 11,611 & 4,945 & 2,738 & 650 & 2,048 & 11 \\
\hline $20 \mathrm{~mL} /$ ton of coal $(9 / 29)$ & 5.66 & 119 & 1 & 6,223 & 1,864 & 1,365 & 647 & 1,028 & 12 \\
\hline $20 \mathrm{~mL} /$ ton of coal $(9 / 30)$ & 5.82 & 120 & 3 & 6,151 & 1,699 & 1,271 & 612 & 971 & 14 \\
\hline
\end{tabular}

Table 15. Results of FGD Solid Sample Analyses for the TMT Steady State Test (mg/g unless noted otherwise)

\begin{tabular}{|c|c|c|c|c|c|c|c|c|}
\hline \multirow[b]{2}{*}{ TMT-15 Addition Rate (Date) } & \multirow{2}{*}{$\begin{array}{l}\text { Slurry } \\
\text { Wt } \% \\
\text { Solids }\end{array}$} & \multirow{2}{*}{$\begin{array}{l}\text { Solids } \\
\text { Wt } \% \\
\text { Inerts }\end{array}$} & \multicolumn{5}{|c|}{ Solids Analysis, mg/g } & \multirow{2}{*}{$\begin{array}{l}\text { Solids } \\
\text { Wt\% } \\
\text { Gypsum }\end{array}$} \\
\hline & & & $\mathrm{Ca}$ & Mg & $\mathrm{SO}_{4}$ & $\mathrm{SO}_{3}$ & $\mathrm{CO}_{3}$ & \\
\hline Baseline [no TMT] (9/28) & 13.2 & 1.33 & 224 & 1 & 533 & $<1$ & 4 & 95.5 \\
\hline $20 \mathrm{~mL} /$ ton of coal (9/29) & 11.9 & 1.21 & 228 & 1 & 530 & $<1$ & 3 & 95.0 \\
\hline $20 \mathrm{~mL} /$ ton of coal $(9 / 30)$ & 12.2 & 0.99 & 228 & $<1$ & 540 & $<1$ & 4 & 96.8 \\
\hline
\end{tabular}

The liquor analyses show that concentrations of highly soluble species such as magnesium, sodium, and chloride dropped significantly from September 28 to September 29, and remained at the lower level through September 30. The reason for this drop is not clear. It is possible that the concentrations of these soluble species built up during the first 24+ hours of operation, where there was no blow down of slurry from the wet FGD pilot, then stabilized at the lower concentrations once regular blow down of slurry and makeup of fresh water began. Note that the lower concentrations seen on September 29 and 30 are more in line with what was measured during the parametric tests in April, as shown previously in Table 8.

\section{Mercury Balance Calculations}

The data presented and discussed above were used to calculate mercury balances around the wet FGD pilot unit. Two types of balances were calculated. One was to determine the extent to which the mercury in the flue gas was represented in the FGD blow down slurry. Since reliable flue gas mercury concentration data were only available for the last day of the steady-state TMT addition test, the mercury balance was calculated only for those data.

The second type of mercury balance was to calculate the extent to which the mercury in the FGD blow down slurry was recovered in the hydrocyclone overflow and underflow samples. Since 
samples were collected on three days $(9 / 28,9 / 29$, and 9/30) the balances were calculated for all three days.

For the first type of mercury balance, the Ontario Hydro data were used to determine the flue gas flow rate to the wet FGD pilot and the amount of mercury removed from the flue gas across the FGD absorber. $\mathrm{SO}_{2}$ analyzer spot-check data were used to determine the average FGD inlet and outlet $\mathrm{SO}_{2}$ concentrations, and thus the amount of $\mathrm{SO}_{2}$ removed and the amount of gypsum byproduct formed per unit time. These two sets of data were used to predict how much mercury should be present in the FGD blow down slurry per unit mass of gypsum byproduct in the slurry. The results are summarized in the following paragraph.

The $\mathrm{SO}_{2}$ analyzer data showed that the FGD inlet concentration averaged about 318 ppmv (dry basis) while the outlet averaged 14 ppmv. This corresponds with just over $95 \% \mathrm{SO}_{2}$ removal. The flue gas flow rate to the wet FGD system was measured at $886 \mathrm{dscfm}$ (at $68^{\circ} \mathrm{F}$ ) during the Ontario Hydro measurements. These data were used to calculate a gypsum byproduct production rate of $3390 \mathrm{~g} / \mathrm{hr}$. The Ontario Hydro data showed an average FGD inlet total mercury concentration of $6.3 \mu \mathrm{g} / \mathrm{Nm}^{3}$ at the actual FGD inlet $\mathrm{O}_{2}$ concentration, $10.2 \%$ (the same basis at which the $\mathrm{SO}_{2}$ concentrations were measured), and $61 \%$ mercury removal (see Table 9). This corresponds with a mercury removal mass rate of $5400 \mu \mathrm{g} / \mathrm{hr}$. Combining these two rates results in an expected mercury content of the FGD blow down slurry of $1.6 \mu \mathrm{g} / \mathrm{g}$ of FGD solid byproduct. The value measured for the FGD blow down slurry for 9/30, as shown in Table 12, was about $20 \%$ higher at $1.9 \mu \mathrm{g} / \mathrm{g}$ (including the small contribution of mercury in the slurry liquor). Although the two values do not agree exactly, agreement with $20 \%$ generally represents acceptable closure for a balance. This minor discrepancy could easily be an artifact of small measurement errors in mercury concentrations, $\mathrm{SO}_{2}$ concentrations, and flow rate measurements.

Furthermore, there is a potential for mercury concentrations having varied somewhat during periods when Ontario Hydro measurements were not being conducted. The gas data represent actual measurements made late in the day on September 29 and in the morning and early afternoon of September 30. However, the FGD reaction tank residence time was estimated at 50 hours. The lignite and PRB coal mercury concentration data in Table 10 show that the fuel mercury concentrations were decreasing over the period of September 28 through September 30. Thus, the blow down solids represent mercury capture over the previous two days, during periods that the fuel mercury concentrations were higher. Considering the residence time effect, an FGD blow down slurry mercury content of $1.9 \mu \mathrm{g} / \mathrm{g}$ would make sense even though the gas data predict a lower value of $1.6 \mu \mathrm{g} / \mathrm{g}$.

In the second type of mercury balance, the FGD blow down and hydrocyclone overflow and underflow wt $\%$ solids data from Table 12 were used to solve for the percentages of the blow down liquor and solids that reported to the overflow and underflow. Once these percentages were calculated, the mercury concentrations of each stream were used to calculate the extent to which the mercury in the blow down slurry was accounted for in the hydrocyclone overflow and underflow streams. The results of the total mass distribution calculations are summarized in Table 16 and of the mercury balance calculations in Table 17. 
Table 16. Summary of Hydrocyclone Overall Mass Balance Estimates

\begin{tabular}{|c|c|c|c|c|c|}
\hline \multirow[b]{2}{*}{ Date } & \multirow{2}{*}{$\begin{array}{l}\text { TMT-15 } \\
\text { Dosage } \\
\text { (mL/ton of } \\
\text { coal) }\end{array}$} & \multicolumn{2}{|c|}{$\begin{array}{l}\% \text { of FGD Blow Down Slurry } \\
\text { Liquor }\end{array}$} & \multicolumn{2}{|c|}{$\begin{array}{l}\% \text { of FGD Blow Down Slurry } \\
\text { Solids }\end{array}$} \\
\hline & & HC Overflow & HC Underflow & HC Overflow & HC Underflow \\
\hline 9/28/2005 & 0 (baseline) & 81 & 19 & 21 & 79 \\
\hline 9/29/2005 & 20 & 83 & 17 & 20 & 80 \\
\hline 9/30/2005 & 20 & 84 & 16 & 25 & 75 \\
\hline
\end{tabular}

Table 17. Summary of Hydrocyclone Mercury Balance Calculations

\begin{tabular}{|l|l|l|l|l|l|l|}
\hline & \multirow{2}{*}{$\begin{array}{l}\text { TMT-15 } \\
\text { Dosage } \\
\text { Date }\end{array}$} & \multicolumn{4}{l}{ \% of FGD Blow Down Slurry Mercury Content } \\
\cline { 3 - 7 } & coal) & $\begin{array}{l}\text { HC Over- } \\
\text { flow Liquor }\end{array}$ & $\begin{array}{l}\text { HC Over- } \\
\text { flow Solids }\end{array}$ & $\begin{array}{l}\text { HC Under- } \\
\text { flow Liquor }\end{array}$ & $\begin{array}{l}\text { HC Under- } \\
\text { flow Solids }\end{array}$ & $\begin{array}{l}\text { Total Hg } \\
\text { Recovery }\end{array}$ \\
\hline $9 / 28 / 2005$ & 0 (baseline) & 6.3 & 20 & 1.2 & 27 & 54 \\
\hline $9 / 29 / 2005$ & 20 & 1.4 & 52 & 0.3 & 30 & 84 \\
\hline $9 / 30 / 2005$ & 20 & 0.6 & 59 & 0.2 & 18 & 78 \\
\hline
\end{tabular}

The results in Table 16 show the expected distribution of solids and liquor in the hydrocyclone outlet streams: most of the solids end up in the underflow and most of the liquor ends up in the overflow. The results in Table 17 show reasonable recovery percentages for the mercury in the FGD blow down in the hydrocyclone product streams for the two TMT test day samples ( 84 and $78 \%)$, but poor recovery for the baseline sample (54\%).

However, as stated in the footnote to Tables 11 and 12, there was a question about the actual wt\% solids concentration of the hydrocyclone overflow sample from the baseline test day.

Because the originally measured value was believed to be in error, an assumed wt $\%$ value was used for the mass balance calculations in Table 16 and may have contributed to the low mercury recovery in Table 17. Also, the solids mercury concentrations used for these calculations were from the samples filtered and analyzed off site. These samples had ample time for mercury in the liquor to adsorb onto the solids. For the TMT tests, there was little mercury in the liquor, so this possible bias on the solids mercury concentrations was insignificant. However, for the baseline sample, where the mercury in the liquor accounted for $13 \%$ of the mercury in the whole slurry, adsorption of mercury from the liquor to the solids in the samples filtered off site may have biased the solid phase mercury concentration values reported in Table 12. Such a bias could have adversely affected the mercury recovery calculations in Table 17.

In summary, the mercury balance closures shown above for the comparison of slurry and flue gas data for September 30, and for the hydrocyclone product streams versus the FGD blow down for the two days of TMT addition show acceptable closure for pilot unit testing of this type. These 
balances were all based on the slurry solids analysis results in Table 12. Although not shown in this report, similar mass balance calculations were conducted based on the solids analysis results shown in Table 11, and showed much poorer closures.

These results support the theory that the original solids analysis data reported in Table 11 reflected biases in solid mercury concentration measurements, and that these biases were corrected with the analyses of samples filtered off site, as reported in Table 12. The original bias was most likely introduced when sample aliquots were only partially filtered to recover solids for subsequent mercury analyses. Sampling and preservation procedures have been revised to avoid such a bias in the future, by collecting smaller aliquots and filtering the entire slurry sample to recover a solid sample.

\section{Task 4: Pilot JBR Parametric Additive Tests at Plant Yates}

A series of parametric TMT-15 additive tests were conducted on the 1-MW pilot JBR at Plant Yates in August 2005, while operating in LSFO mode. The 8-day parametric test effort, including start up and shut down efforts, measured baseline (no TMT) performance and included three subsequent tests at increasing dosage rates of TMT-15. The TMT-15 dosages tested included 0 (baseline), 2.5, 7.5, and $20 \mathrm{~mL} /$ ton of coal fired.

\section{Mercury Removal Data}

Mercury removal data were measured for the pilot JBR FGD system by mercury SCEM, using one analyzer each at the FGD inlet and outlet. The results are summarized in Table 18.

Table 18. Daily Average Mercury SCEM Data for Pilot JBR TMT-15 Tests

\begin{tabular}{|c|c|c|c|c|c|c|c|c|c|}
\hline \multirow[b]{2}{*}{ Date } & \multirow{2}{*}{$\begin{array}{l}\text { TMT-15 } \\
\text { Dose, } \\
\text { mL/ton } \\
\text { of coal } \\
\text { fired }\end{array}$} & \multicolumn{2}{|c|}{$\begin{array}{l}\text { JBR Inlet } \\
\mathrm{Hg}, \mu \mathrm{g} / \mathrm{Nm}^{3} \\
@ 3 \% \mathrm{O}_{2}\end{array}$} & \multicolumn{2}{|c|}{$\begin{array}{l}\text { JBR Outlet } \\
\mathrm{Hg}, \mu \mathrm{g} / \mathrm{Nm}^{3} \\
@ 3 \% \mathrm{O}_{2}\end{array}$} & \multirow{2}{*}{$\begin{array}{l}\mathrm{Hg} \\
\text { Oxidation } \\
\text { at Pilot } \\
\text { FGD } \\
\text { Inlet, \% }\end{array}$} & \multirow{2}{*}{$\begin{array}{l}\text { Total Hg } \\
\text { Removal } \\
\text { by FGD, } \\
\%\end{array}$} & \multirow{2}{*}{$\begin{array}{l}\mathrm{Hg}^{+2} \\
\text { Removal } \\
\text { by FGD, } \\
\%\end{array}$} & \multirow{2}{*}{$\begin{array}{l}\mathrm{Hg}^{0} \\
\text { Removal } \\
\text { by FGD, } \\
\%\end{array}$} \\
\hline & & $\begin{array}{l}\text { Total } \\
\mathrm{Hg}\end{array}$ & $\mathrm{Hg}^{0}$ & $\begin{array}{l}\text { Total } \\
\mathrm{Hg}\end{array}$ & $\mathrm{Hg}^{0}$ & & & & \\
\hline 8/18/2005 & 0 & 2.3 & $0.3^{*}$ & 2.1 & 2.1 & $87^{*}$ & 11 & $103^{*}$ & $-632^{*}$ \\
\hline 8/19/2005 & 2.5 & 3.8 & 1.6 & 4.5 & 2.8 & 58 & -16 & 25 & -72 \\
\hline 8/20/2005 & 7.5 & 3.6 & 1.9 & 2.9 & 2.5 & 45 & 20 & 78 & -32 \\
\hline 8/21/2005 & 20 & 3.6 & 2.2 & 4.0 & 3.7 & 39 & -11 & 80 & -64 \\
\hline
\end{tabular}

*It is suspected that solids buildup on the IGS filter at the inlet sample was causing oxidation of elemental mercury in the inlet flue gas sample, biasing these results; the IGS filter was replaced for subsequent days

In general, the pilot JBR outlet SCEM data are not believed to be reliable. As described in Section 2, the pilot JBR did not have a mist eliminator, which apparently led to significant slurry carryover into the pilot JBR outlet duct where the outlet SCEM sample was collected. The IGS filters used to separate a gas sample to go to the SCEM are typically heated to greater than $400^{\circ} \mathrm{F}$ to minimize mercury adsorption on any solids that might collect on IGS filter surfaces. However, 
if there is significant FGD liquor and solids carryover in the gas sampled, the mercury in the liquor and/or on the solids can be evaporated and/or desorbed at the elevated operating temperature of the IGS filter. In this circumstance, the JBR outlet total mercury concentration data are believed to be biased high, and the outlet mercury speciation (total versus elemental) are not reliable.

As an example, the data for testing on August 19 and August 21 show negative overall mercury removal, which would require mercury to be desorbing from the JBR liquor at a higher rate than oxidized mercury is being absorbed from the inlet flue gas. Furthermore, the apparent removal percentage for oxidized mercury for August 19, 25\% does not seem realistic, as the JBR represents an effective flue gas contactor that should absorb oxidized mercury at high efficiency. Even the apparent oxidized mercury removal efficiency values for August 20 and 21, at $78 \%$ and $80 \%$, seem low.

Although the data from all four days included in the table show evidence of elemental mercury re-emissions from the JBR, these data are not seen as being reliable for the reasons described above. Therefore, the SCEM data cannot be used to reliably determine whether there was any reemission from the pilot JBR under baseline (no TMT) conditions, or whether TMT-15 addition had any effect on controlling re-emissions.

\section{Mercury Concentrations in FGD Liquor and Solids}

Because the gas-phase mercury concentration data were considered unreliable, data analysis from the pilot JBR TMT-15 additive tests focused on pilot JBR liquor and solid mercury concentration data. The results of these analyses are summarized in Table 19. Included in the table are the results of mercury analyses on blow down slurry samples from the full-scale JBR for August 18 and 21. Also shown are mercury analysis results for hydrocyclone overflow and underflow samples from treating blow down slurry from the pilot JBR.

Note that, as shown previously in Figure 5, the JBR blow down slurry (pilot or full scale) is a slipstream of the same slurry that is recirculated to the flue gas quench nozzles in the JBR inlet duct. This slurry is pumped from the reaction zone at the bottom of the JBR on a continuous basis, and thus is expected to be representative of the reaction zone slurry at the time the sample is collected.

The pilot-scale JBR had been charged with blow down slurry from the full-scale JBR the day before the baseline samples were collected on August 18, and the blow down slurry was diluted with makeup water. The results for the baseline test on August 18 show that the liquor mercury concentration in the pilot JBR was about half that of the full-scale JBR, and that the wt $\%$ solids in the pilot JBR slurry was a factor of 11 lower than the wt\% solids in the full-scale JBR. This suggests that the pilot JBR was operating very dilute compared to the full-scale JBR. 
Table 19. Pilot JBR Blow Down Slurry Liquor and Solids Mercury Concentrations

\begin{tabular}{|c|c|c|c|c|}
\hline Sample & $\begin{array}{l}\text { Liquor } \mathrm{Hg} \\
\text { Concentration } \\
\text { ( } \mu \mathrm{g} / \mathrm{L})\end{array}$ & $\begin{array}{l}\text { Wt\% } \\
\text { Solids }\end{array}$ & $\begin{array}{l}\text { Solids } \mathrm{Hg} \\
\text { Concentration } \\
(\mu \mathrm{g} / \mathrm{g})\end{array}$ & $\begin{array}{l}\% \text { of FGD Blow } \\
\text { Down Hg in Slurry } \\
\text { Found in Liquor }\end{array}$ \\
\hline \multicolumn{5}{|l|}{ Baseline [no TMT] (8/18/05): } \\
\hline $\begin{array}{l}\text { Full-scale JBR Blow Down } \\
\text { Slurry }\end{array}$ & 14.6 & 12.1 & 0.10 & 52 \\
\hline Pilot JBR Blow Down Slurry & 7.52 & 1.1 & 0.29 & 70 \\
\hline Hydrocyclone Overflow & 7.95 & 0.44 & 0.42 & - \\
\hline Hydrocyclone Underflow & 9.33 & 19.8 & 0.07 & - \\
\hline \multicolumn{5}{|c|}{ TMT-15 at $2.5 \mathrm{~mL} /$ ton of coal $(8 / 19 / 05)$ : } \\
\hline Pilot JBR Blow Down Slurry & 8.79 & 0.71 & 0.09 & 93 \\
\hline Hydrocyclone Overflow & 9.84 & 0.29 & 0.52 & - \\
\hline Hydrocyclone Underflow & 8.45 & 21.1 & 0.07 & - \\
\hline \multicolumn{5}{|c|}{ TMT-15 at $7.5 \mathrm{~mL} /$ ton of coal $(8 / 20 / 05)$ : } \\
\hline Pilot JBR Blow Down Slurry & 0.67 & 4.9 & 0.20 & 6.2 \\
\hline Hydrocyclone Overflow & 0.48 & 3.2 & 0.55 & - \\
\hline Hydrocyclone Underflow & 1.18 & 35.6 & 0.08 & - \\
\hline \multicolumn{5}{|c|}{ TMT-15 at $20 \mathrm{~mL} /$ ton of coal (8/21/05): } \\
\hline $\begin{array}{l}\text { Full-scale JBR Blow Down } \\
\text { Slurry }\end{array}$ & 13.3 & 10.9 & 0.08 & 56 \\
\hline Pilot JBR Blow Down Slurry & $<0.25$ & 4.9 & 0.15 & $<1.6$ \\
\hline Hydrocyclone Overflow & $<0.25$ & 2.0 & 0.76 & - \\
\hline Hydrocyclone Underflow & $<0.25$ & 43.1 & 0.05 & - \\
\hline
\end{tabular}

However, analyses of highly soluble liquid phase species from the pilot- and full-scale JBR from August 18, presented later in this subsection, show that the pilot-scale JBR was only 10 to $20 \%$ more dilute than the full-scale JBR. The concentrations of these highly soluble species provide a better indication of the dilution of the slurry in the pilot JBR than mercury, which can be adsorped on solids or re-emitted, or suspended solids, which can become stratified and poorly represented in a grab sample. 
The comparison of soluble liquid-phase species concentrations, which show little dilution, and $\mathrm{wt} \%$ solids levels in the pilot- and full-scale JBR, which show an order of magnitude difference in wt $\%$, indicates that the pilot JBR blow down slurry sample was biased low in solids content. This was most likely caused by solids accumulation at the bottom of the pilot JBR. As indicated in Section 2, the pilot JBR did not have a mechanical agitator, and relied on the flow of forced oxidation air at the bottom of the reaction zone to keep solids suspended. The wt\% solids data from August 18 suggest that the forced oxidation air was not effective at keeping the solids suspended, leading to the very low wt $\%$ solids levels measured in the slurry blow down sample.

The data in Table 19 can be reviewed to determine the effects of TMT-15 addition. In the baseline sample from August 18, 70\% of the mercury in the pilot JBR slurry sample was found in the liquor, although this percentage may be biased by solids stratification as discussed above. At the lowest TMT-15 dosage, $2.5 \mathrm{~mL} /$ ton of coal fired, the percentage in the liquid phase actually went up, although this may also be an artifact of solids stratification. As the TMT-15 rate was increased, the percentage of the slurry mercury in the liquid phase decreased, with the percentage at the highest rate, $20 \mathrm{~mL} /$ ton of coal fired, dropping to less than $1.6 \%$ (the analytical detection limit). The corresponding liquid-phase mercury concentrations dropped from $7.5 \mu \mathrm{g} / \mathrm{L}$ at baseline August 18) to below the measurement detection limit of $0.25 \mu \mathrm{g} / \mathrm{L}$ at the highest TMT-15 dosage rate.

The data for the hydrocyclone overflow and underflow samples generally showed expected trends. The overflow tended to have lower wt $\%$ solids than the blow down but higher solids mercury concentrations, while the underflow had higher wt \% solids and lower solids mercury concentrations than the blow down. In spite of the fact that most of the absorbed mercury was shifted from the liquor to the solids by the addition of TMT, fines removal from the product gypsum resulted in the product from the highest TMT-15 dosage test having a 30\% lower mercury concentration than the baseline (no TMT) product solids from August 18. Note that all of the product solids from the pilot JBR underflow had very low mercury concentrations (less than $0.1 \mu \mathrm{g} / \mathrm{g})$.

\section{FGD Solids Particle Size Analyses}

Samples of the pilot JBR blow down, hydrocyclone overflow and underflow from the baseline test (August 18) and the $20 \mathrm{~mL} /$ ton of coal TMT test (August 21) were sent out for particle size analyses. The same technique was used as for the samples from the Monticello pilot FGD tests. The results of those particle size analyses are summarized in Table 20.

The particle size analyses generally show the expected trend, that the hydrocyclone overflow solids are finer than the FGD blow down solids (hydrocyclone feed) while the underflow solids are coarser. An exception was the baseline test underflow solid sample (August 18), which was measured to have about the same particle size distribution as the feed (within experimental error). As did the Monticello steady-state TMT additive test results, these data show quite a bit of overlap in the particle size distributions of the hydroclone overflow and underflow. 
Table 20. Summary of Particle Size Analyses on Solid Samples from Steady-state TMT Additive Test

\begin{tabular}{|l|l|l|l|l|l|}
\hline $\begin{array}{l}\text { Test } \\
\text { Date }\end{array}$ & $\begin{array}{l}\text { TMT Dosage, } \\
\mathbf{m L} / \text { ton of coal }\end{array}$ & Sample & $\mathbf{D}_{10}{ }^{*}, \mu \mathbf{m}$ & $\mathbf{D}_{\mathbf{5 0}}{ }^{*}, \mu \mathbf{m}$ & $\mathbf{D}_{\mathbf{9 0}}{ }^{*}, \mu \mathbf{m}$ \\
\hline $8 / 18$ & \multirow{2}{*}{0 (Baseline) } & Scrubber Blow Down & 16.1 & 37.7 & 72.0 \\
\cline { 3 - 6 } & & Fines (HC Overflow) & 6.4 & 22.8 & 50.2 \\
\cline { 3 - 6 } & \multirow{2}{*}{$8 / 21$} & Product Gypsum (HC Underflow) & 11.5 & 34.2 & 67.8 \\
\hline & Scrubber Blow Down & 14.5 & 44.6 & 89.6 \\
\cline { 3 - 6 } & Fines (HC Overflow) & 6.1 & 32.1 & 71.6 \\
\cline { 3 - 6 } & Product Gypsum (HC Underflow) & 24.3 & 54.8 & 99.7 \\
\hline
\end{tabular}

*Particle size at which $10 \%, 50 \%$, or $90 \%$ of the sample mass is smaller

Hydrocyclones typically do not make a sharp separation at a given particle size, but instead tend to produce two streams with overlapping "bell shaped" particle size distributions, as illustrated in Figure 10 . For both sets of samples, the $\mathrm{D}_{10}$ of the underflow was smaller than the $\mathrm{D}_{50}$ of the overflow solids. This says that more than $10 \%$ of the product gypsum was finer than the median particle size of the fines. Since the fines samples had a considerably higher mercury concentration than the product gypsum (see Table 19), it is likely that the fine particles that remain in the product gypsum account for most of its mercury content.

\section{FGD Operating Conditions}

The pilot JBR was operated on day shift only, typically from about 8:00 a.m. to 6:00 p.m. The desired operating conditions for the pilot JBR were for the $\mathrm{pH}$ in the absorption zone to be controlled at 4.0, and the JBR pressure drop be greater than 10 in. $\mathrm{H}_{2} \mathrm{O}$. The pressure drop was generally controlled above this level, but as discussed below, the $\mathrm{pH}$ measurement and control proved to be problematic, apparently due to inadequate mechanical agitation. The flue gas flow rate was intended to run as high as the pilot JBR fan would allow. However, the maximum fan speed was limited by "tripping" the variable frequency drive (VFD) for the fan if the set point was raised too high or at high ambient temperature at the VFD. The observed flue gas flow rate varied from about 2000 to $4000 \mathrm{acfm}$ at pilot JBR inlet conditions, as measured by the inlet multi-point pitot. However, some of this flow variation appeared to be in the flow measurement rather than in the actual flow rate. The flue gas inlet temperature upstream of the quench nozzles typically ran $270^{\circ} \mathrm{F}$ to $280^{\circ} \mathrm{F}$ after the pilot JBR had operated several hours. The forced oxidation air rate, which also provided slurry agitation (although apparently inadequately), was typically 25 to $30 \mathrm{scfm}$. The oxidation air rate tended to be limited by the forced oxidation air pressure available from the full-scale JBR forced oxidation air header on the side nearest the pilot JBR. The slurry level in the JBR was varied between about 118 to 125 inches. 


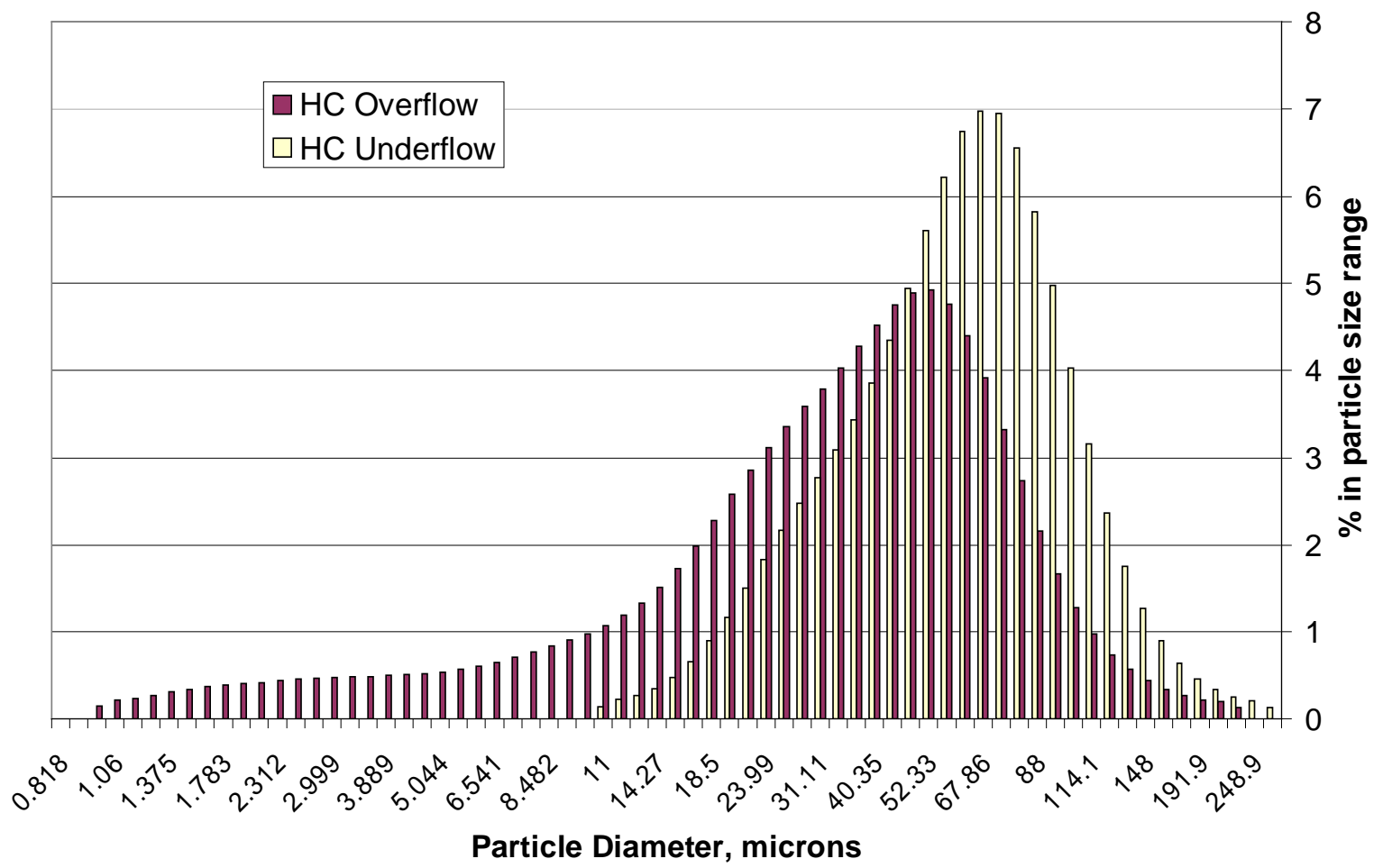

Figure 10. Hydrocyclone Overflow and Underflow Particle Size Data for the $20 \mathrm{~mL} / \mathrm{ton}$ of Coal TMT-15 Test at Plant Yates

The CEM on the full-scale JBR typically showed the inlet $\mathrm{SO}_{2}$ concentration to be about 650 ppmv, although there was an excursion the morning of August 19 up to 975 ppmv. The inlet $\mathrm{SO}_{2}$ concentration at the pilot JBR was checked periodically with gas absorption tubes. These measurements ranged from 505 to 750 ppmv (wet basis). The pilot JBR outlet $\mathrm{SO}_{2}$ concentrations were also checked periodically with gas absorption tubes. These showed widely varying $\mathrm{SO}_{2}$ removal percentages, with outlet $\mathrm{SO}_{2}$ concentrations varying from a high of 500 ppmv to as low as 10 ppmv (wet basis). The wide variation in outlet $\mathrm{SO}_{2}$ concentration was apparently an adverse effect of poor agitation and $\mathrm{pH}$ control in the absorption zone of the JBR.

Samples were collected of the pilot JBR blow down slurry for the second day of the baseline test (August 18) and each of the three TMT-15 dosage tests. Samples were also collected from the full-scale JBR on the same days as the baseline pilot JBR test (August 18) and the final TMT-15 pilot JBR test (August 21). The results of chemical analyses of these samples are summarized in Table 21 for the FGD liquor samples and Table 22 for the FGD solids.

Looking at the concentrations of liquid-phase species, it is of interest to observe the concentrations of the highly soluble ions in the FGD liquors, chloride $(\mathrm{Cl})$, magnesium $(\mathrm{Mg})$ and sodium $(\mathrm{Na})$. Concentrations of these species can be compared to determine how dilute the pilot JBR was operating compared to the full-scale JBR. For the August 18 data, the pilot JBR concentrations of $\mathrm{Cl}, \mathrm{Mg}$, and $\mathrm{Na}$ were $92 \%, 82 \%$, and $88 \%$, respectively, of the full-scale JBR results. This suggests that the pilot JBR was only 10 to $20 \%$ more dilute than the full-scale JBR. 
As shown in Table 21, though, the wt $\%$ solids in the pilot JBR blow down slurry was only $1.1 \%$ versus 12.1 for the full-scale JBR. Since the soluble salts show only a 10 to $20 \%$ dilution in the pilot JBR, while the solids show a factor of 11 lower solids content, the conclusion can be made that solid were settling in the bottom of the pilot JBR and were not reflected in the blow down slurry. As discussed previously, this is most likely an effect of the pilot JBR not having a mechanical agitator.

Table 21. Results of FGD Liquor Sample Analyses for the TMT Parametric Tests (mg/L unless noted otherwise)

\begin{tabular}{|c|c|c|c|c|c|c|c|c|c|c|}
\hline TMT-15 Addition Rate (Date) & PH & $\begin{array}{l}\text { Temp. } \\
{ }^{\circ} \mathrm{F}\end{array}$ & ORP & $\mathrm{SO}_{3}$ & $\mathrm{SO}_{4}$ & $\mathrm{Cl}^{-}$ & Mg & $\mathrm{Ca}$ & $\mathrm{Na}$ & $\mathrm{CO}_{3}$ \\
\hline Full-scale JBR (8/18) & 4.72 & 124 & 430 & 5 & 3184 & 2636 & 659 & 1437 & 89 & 35 \\
\hline $\begin{array}{l}\text { Pilot JBR Baseline [no TMT] } \\
(8 / 18)\end{array}$ & 4.02 & 125 & 457 & 2 & 2100 & 2435 & 516 & 1439 & 78 & 88 \\
\hline $\begin{array}{l}\text { Pilot JBR } 2.5 \mathrm{~mL} / \text { ton of coal } \\
(8 / 19)\end{array}$ & 3.03 & 125 & 524 & 1 & 2003 & 3362 & 588 & 1824 & 91 & 94 \\
\hline $\begin{array}{l}\text { Pilot JBR } 7.5 \mathrm{~mL} / \text { ton of coal } \\
(8 / 20)\end{array}$ & 5.15 & 125 & 266 & 2 & 1596 & 2864 & 579 & 1415 & 84 & 36 \\
\hline $\begin{array}{l}\text { Pilot JBR } 20 \mathrm{~mL} / \text { ton of coal } \\
(8 / 21)\end{array}$ & 6.08 & 124 & 177 & 34 & 1711 & 2639 & 568 & 1408 & 88 & 157 \\
\hline Full-scale JBR (8/21) & 4.38 & 124 & 433 & 7 & 1646 & 2841 & 583 & 1431 & 85 & 65 \\
\hline
\end{tabular}

Table 22. Results of FGD Solid Sample Analyses for the TMT Parametric Tests

\begin{tabular}{|c|c|c|c|c|c|c|c|c|}
\hline \multirow[b]{2}{*}{ TMT-15 Addition Rate (Date) } & \multirow{2}{*}{$\begin{array}{l}\text { Slurry } \\
\text { Wt\% } \\
\text { Solids } \\
\end{array}$} & \multirow{2}{*}{$\begin{array}{l}\text { Solids } \\
\text { Wt\% } \\
\text { Inerts } \\
\end{array}$} & \multicolumn{5}{|c|}{ Solids Analysis, $\mathrm{mg} / \mathrm{g}$} & \multirow{2}{*}{$\begin{array}{c}\text { Solids } \\
\text { Wt } \% \\
\text { Gypsum }\end{array}$} \\
\hline & & & $\mathrm{Ca}$ & $\mathrm{Mg}$ & $\mathrm{SO}_{4}$ & $\mathrm{SO}_{3}$ & $\mathrm{CO}_{3}$ & \\
\hline Full-scale JBR (8/18) & 12.1 & 1.7 & 227 & $<1$ & 538 & $<1$ & 2 & 96.4 \\
\hline Pilot JBR Baseline [no TMT] (8/18) & 1.1 & 1.8 & 236 & $<1$ & 493 & $<1$ & 43 & 88.4 \\
\hline Pilot JBR $2.5 \mathrm{~mL} /$ ton of coal (8/19) & 0.7 & 2.2 & 224 & $<1$ & 527 & $<1$ & 5 & 94.5 \\
\hline Pilot JBR $7.5 \mathrm{~mL} /$ ton of coal (8/20) & 4.9 & 1.6 & 236 & 1 & 491 & $<1$ & 53 & 88.0 \\
\hline Pilot JBR $20 \mathrm{~mL} /$ ton of coal (8/21) & 4.9 & 1.9 & 251 & 1 & 443 & 1 & 98 & 79.4 \\
\hline Full-scale JBR (8/21) & 10.9 & 2.0 & 223 & $<1$ & 539 & $<1$ & 2 & 96.5 \\
\hline
\end{tabular}

The liquor analysis results show that the soluble species concentrations remained relatively constant over the pilot test period. At the time of the highest TMT-15 rate test on August 21, the pilot JBR soluble species concentrations were nearly identical to those of the full-scale JBR (within $\pm 7 \%$ ).

The $\mathrm{pH}$ values for the pilot JBR showed the effects of the poor agitation on the ability to control limestone makeup rates. Because of the poor mixing, the $\mathrm{pH}$ in the pilot JBR varied over a wide range. The blow down slurry sample $\mathrm{pH}$ values ranged from 3.03 to 6.08 . Generally, the $\mathrm{pH}$ of 
the blow down slurry showed poor correlation with the $\mathrm{pH}$ measured by the $\mathrm{pH}$ controller, located higher up in the reaction tank of the pilot JBR. Because of this poor correlation, as the testing progressed, $\mathrm{pH}$ control was done with manual limestone dosing to the pilot JBR rather than relying on the feedback signal from the $\mathrm{pH}$ controller.

The oxidation-reduction potential (ORP) readings from the pilot JBR were observed to correlate inversely with $\mathrm{pH}$. At lower $\mathrm{pH}$ the ORP was higher and at higher $\mathrm{pH}$ the ORP trended lower. This indicates that the liquor was more highly oxidizing at lower $\mathrm{pH}$, which is consistent with previous FGD experience that generally shows higher sulfite oxidation at lower $\mathrm{pH}$.

The solid analyses show further adverse effects of the apparent poor mixing in the JBR reaction zone. Although all of the solids samples were highly oxidized (very little sulfite $\left[\mathrm{SO}_{3}{ }^{{ }}\right]$in the solids) several of the samples showed high carbonate content and low gypsum purity $(<90 \%)$, indicative of high $\mathrm{pH}$ excursions and/or poor mixing of carbonate-rich solids in the absorption zone of the JBR.

\section{Mercury Balance Calculations}

Given that the slurry solids in the JBR were apparently stratified by the lack of mechanical agitation, that the SCEM gas phase mercury concentration data were not considered to be reliable, and that the pilot JBR was not operated around the clock to achieve true steady state operation, no attempt was made to close a mercury balance around the pilot JBR. Overall mass and mercury balances were calculated around the hydrocyclone when blowing down slurry from the pilot JBR, though. Table 23 shows the overall mass balance estimate around the hydrocyclone, based on feed, overflow and underflow wt $\%$ solids values. Table 24 shows the mercury balances around the hydrocyclone based on the estimates from Table 23 and the mercury analysis results from Table 19.

The mercury balance results show reasonably close closures for the samples from August 18 and 19 , but nearly $200 \%$ recovery of the mercury in the pilot JBR blow down slurry in the hydroclone overflow and underflow for the samples from August 20 and 21. For those two days, it appears that the amount of mercury in the hydrocyclone overflow solids is over-reported. This suggests that either the wt\% solids values for those samples are biased high, and/or the mercury concentrations are biased high.

There are two possible reasons for the wt\% solids and/or solids mercury concentration bias seen in the mercury balance closures for August 20 and 21. One is a possible sample filtering and preservation bias discussed previously for the Monticello steady-state TMT additive test. The other is a possible sample time bias. The JBR blow down (hydrocyclone feed) sample set typically takes several minutes to collect, because the preserved FGD liquor samples are pressure filtered at the point of sample collection into separate prepared bottles for the various analytes. Given the evidence of stratification of solids in the lower portions of the JBR where the recycle pump takes suction, it is possible that the hydrocyclone feed slurry composition varied during the time that elapsed between when the hydrocyclone feed samples were collected and when the overflow and underflow samples were collected. 
Table 23. Summary of Hydrocyclone Overall Mass Balance Estimates

\begin{tabular}{|l|l|l|l|l|l|}
\hline & \multirow{2}{*}{$\begin{array}{l}\text { TMT-15 } \\
\text { Dosage } \\
\text { Date }\end{array}$} & \multicolumn{3}{|l|}{$\begin{array}{l}\text { \% of FGD Blow Down Slurry } \\
\text { Liquor }\end{array}$} & \multicolumn{3}{l|}{$\begin{array}{l}\text { \% of FGD Blow Down Slurry } \\
\text { Solids }\end{array}$} \\
\cline { 3 - 6 } & HC Overflow & HC Underflow & HC Overflow & HC Underflow \\
\hline $8 / 18 / 2005$ & 0 (baseline) & 96 & 3.6 & 37 & 63 \\
\hline $8 / 19 / 2005$ & 2.5 & 98 & 2.0 & 40 & 60 \\
\hline $8 / 20 / 2005$ & 7.5 & 94 & 6.3 & 57 & 43 \\
\hline $8 / 21 / 2005$ & 20 & 92 & 7.6 & 36 & 64 \\
\hline
\end{tabular}

Table 24. Summary of Hydrocyclone Mercury Balance Calculations

\begin{tabular}{|l|l|l|l|l|l|l|}
\hline \multirow{2}{*}{ Date } & \multirow{2}{*}{$\begin{array}{l}\text { TMT-15 } \\
\text { Dosage } \\
\text { (mL/ton of } \\
\text { coal) }\end{array}$} & \multicolumn{6}{l}{ \% of FGD Blow Down Slurry Mercury Content } \\
\cline { 5 - 8 } & $\begin{array}{l}\text { HC Over- } \\
\text { flow Liquor }\end{array}$ & $\begin{array}{l}\text { HC Over- } \\
\text { flow Solids }\end{array}$ & $\begin{array}{l}\text { HC Under- } \\
\text { flow Liquor }\end{array}$ & $\begin{array}{l}\text { HC Under- } \\
\text { flow Solids }\end{array}$ & $\begin{array}{l}\text { Total Hg } \\
\text { Recovery }\end{array}$ \\
\hline $8 / 18 / 2005$ & 0 (baseline) & 71 & 17 & 3.1 & 4.5 & 96 \\
\hline $8 / 19 / 2005$ & 2.5 & 102 & 16 & 1.8 & 3.4 & 123 \\
\hline $8 / 20 / 2005$ & 7.5 & 4.1 & 149 & 0.7 & 17 & 171 \\
\hline $8 / 21 / 2005$ & 20 & 1.5 & 175 & 0.1 & 21 & 197 \\
\hline
\end{tabular}




\section{CONCLUSION}

The results of these pilot-scale TMT additive tests are not as conclusive as was hoped regarding the effects of adding TMT-15 to FGD slurries to enhance mercury capture by wet FGD systems.

The primary objective of the additive is to prevent or limit mercury re-emissions from wet FGD systems. However, in the first pilot-scale additive parametric tests conducted at Monticello Station, no evidence was seen of re-emissions without the additive, so this objective could not be evaluated. The steady-state TMT-15 additive test conducted later at Monticello had the pilot wet FGD system operating downstream of a gold mercury oxidation catalyst, as previous test results without TMT-15 additive had shown evidence of FGD re-emissions when downstream of this catalyst. The Ontario Hydro method was used to measure re-emissions when operating the pilot wet FGD downstream of the gold catalyst and while adding TMT-15 at $20 \mathrm{~mL} / \mathrm{ton}$ of coal fired. These results show a mean re-emission level of $0.5 \mu \mathrm{g} / \mathrm{Nm}^{3}$, which is about one fourth of the reemissions measured previously without TMT-15. Furthermore, when the $95 \%$ confidence intervals of these measurements are considered, it is possible that no re-emissions were occurring. This could be taken as evidence that TMT-15 addition greatly reduced re-emissions when operating the pilot wet FGD downstream of the gold catalyst. However, the oxidized mercury concentration at the wet FGD pilot inlet during the TMT test was only $25 \%$ of what the concentration had been for the previous test without TMT. When the mean re-emissions are expressed as a percentage of the mean FGD inlet oxidized mercury concentration, the percentages are the same for the two tests. This confounds the finding of whether or not TMT-15 was effective in limiting re-emissions. For the pilot JBR tests conducted at Plant Yates, mercury SCEM data appear to be compromised by excessive scrubber liquor carryover from the pilot JBR into the outlet duct, and thus provide no useful information about re-emissions.

Other expected effects of TMT-15 addition were seen more clearly in these results. TMT-15 was clearly effective in lowering FGD liquor mercury concentrations. During the steady-state pilot FGD TMT-15 test at Monticello, the FGD liquor mercury concentrations were lowered by over an order of magnitude compared to baseline (no TMT addition) values from two days earlier. Since it is liquid-phase mercury reactions that are believed to produce re-emissions, this suggests that TMT-15 would be effective at limiting re-emissions.

Results also show that TMT-15 addition can result in lower gypsum byproduct mercury concentrations if some form of gypsum fines separation is employed. Observed reductions in gypsum mercury concentration varied from $17 \%$ to $29 \%$ in the three series of pilot-scale tests. The effectiveness of TMT-15 in lowering gypsum mercury concentrations appears to be limited by the ability of the FGD blow down slurry dewatering equipment to remove fine particles. Hydrocyclones leave a percentage of fine particles in the underflow slurry, and these fine particles appear to account for much of the mercury that remains in the product gypsum. Other forms of solid separation equipment, that can make a sharper separation of fine particles from the coarser particles, may be able to produce a gypsum byproduct with a lower mercury concentration.

The addition of TMT-15 did not appear to have any adverse effect on the operation of either wet FGD pilot unit. Concentrations of species other than mercury in the FGD liquors did not appear 
to be affected, $\mathrm{SO}_{2}$ removal percentages remained high, and gypsum byproduct particle size distributions were not greatly impacted.

For these reasons, it is recommended that full-scale testing of TMT-15 additive be conducted, as planned as part of Tasks 3 and 5 of this project. The full-scale tests are to be conducted for longer periods than were the pilot tests, which will allow more time to determine if the potential benefits of TMT-15 addition are realized. Furthermore, the full-scale wet FGD systems should have more effective mist eliminator systems than either of the pilot FGD systems tested. This should allow FGD outlet mercury concentration measurements to be made in a flue gas that is relatively free of scrubber carryover, and should improve the quality of mercury re-emission measurements.

Several lessons were learned from these tests that should be reflected in any future testing related to mercury control by wet FGD systems. One is that mist carryover from wet FGD systems can greatly affect mercury concentration measurements by SCEMs that use IGS filters to extract a particulate-free flue gas sample. Pilot wet FGD systems should be equipped with mist eliminators that are as efficient as modern full-scale FGD absorbers to allow accurate mercury concentration measurements in the FGD outlet flue gas by SCEM methods. Alternately, other methods of separating a particulate-free sample that can better deal with mist carryover need to be developed. A second lesson for using SCEMs to evaluate mercury control performance is a reminder that the SCEM computer hard drive needs to be backed up frequently, and/or the complete SCEM output must be recorded elsewhere as it is produced to avoid excessive loss of data on computer failures.

A third lesson learned has to do with FGD slurry sampling to determine solid and liquid phase mercury concentrations. It is clear that liquor samples should be filtered and preserved as soon as possible after sample collection, to avoid biasing the liquor mercury concentration by adsorption onto solids in the slurry before this separation is made. However, it has also become clear that the only way to get a representative solid sample from a whole slurry is to filter the entire slurry sample to recover its solid content. Any partial filtering of the slurry sample may result in a biased mercury concentration in the solids, due to the significant variation in mercury concentration by solid particle size. 


\section{REFERENCES}

1. Tarabocchia, John and Ruediger Peldszus, "Mercury Separation from Flue Gas and Scrub Water with Trimercapto-s-triazine (TMT)," paper presented at the Combined Power Plant Air Pollutant Control Mega Symposium, Washington, D.C., May 19-22, 2003.

2. Blythe, Gary M. "Pilot Testing of Mercury Oxidation Catalysts for Upstream of Wet FGD Systems," Quarterly Technical Progress Report, March 1, 2005 - June 30, 2005. Cooperative Agreement No. DE-FC26-04NT41992, URS Corporation, Austin, Texas 78729. July 2005.

3. Standard Test Method for Elemental, Oxidized, Particulate-Bound and Total Mercury in Flue Gas Generated from Coal-Fired Stationary Sources (Ontario Hydro Method), ASTM International, West Conshohocken, PA, June 2002. D 6784 - 02. 